\title{
Imaging of Thoracic Hydatid Cysts, Point of view of the Radiologist
}

\author{
F. Baadi $^{1 *}$, C. Gakosso ${ }^{1}$, M. Badraoui ${ }^{1}$, B. Boutakioute ${ }^{1}$, M. Ouali Idrissi ${ }^{1}$, N. Cherif Idrissi El Ganouni ${ }^{1}$
}

${ }^{1}$ Radiology Department, Arrazi Hospital, Mohammed VIth Teaching Center, Medical School of Marrakesh, Cadi Ayad University, Marrakesh, Morocco

$\begin{array}{cl}\text { Article History } & \text { Abstract: Hydatidosis is a parasitic disease endemic, and represents a real public health } \\ \text { Received: } 21.01 .2021 & \begin{array}{l}\text { problem in our country. In adult, thoracic hydatidosis represents the second localization } \\ \text { where pulmonary localization is largely predominant. Imaging in particular CT has a } \\ \text { Accepted: } 06.02 .2021\end{array} \\ \text { Published: } 30.04 .2021 & \begin{array}{l}\text { fundamental role in the positive diagnosis and the search for complications. The aim of } \\ \text { our work is to illustrate the radiological aspects of thoracic hydatid cyst, through a } \\ \text { retrospective study of } 40 \text { cases, collected over a period of } 2 \text { years (from January 2017 } \\ \text { to December 2018) at Radiology Service of the Mohammed VI University Hospital }\end{array} \\ \text { Journal homepage: } & \begin{array}{l}\text { Center in Marrakech, Morocco. } \\ \text { Key words: thoracic, hydatid cyst, CT, lung, pleura, mediastinal, parietal, pericardia, } \\ \text { cardiac, vascular, vertebral. }\end{array}\end{array}$

Copyright (C) 2021 The Author(s): This is an open-access article distributed under the terms of the Creative Commons Attribution 4.0 International License (CC BY-NC 4.0) which permits unrestricted use, distribution, and reproduction in any medium for non-commercial use provided the original author and source are credited.

\section{INTRODUCTION}

Hydatidosis is an endemic parasitic disease and represents a real public health problem in our country. Thoracic hydatidosis involves damage to several organs, which have in common their belonging to the thorax. This terminology therefore includes the hydatid cysts of the lung, pleura, mediastinum, diaphragm, ribs, wall, and vertebrae, spinal cord, vascular and heart. Pulmonary involvement is the second location of hydatid cyst after that of the liver. On the other hand, extra-pulmonary thoracic localizations are much rarer, but remain serious, which can be life threatening for any local or general complications that may result from the evolution of the cyst. The diagnosis of this disease based on epidemiological, clinical, biological and radiological arguments rarely by the surgical intervention. The treatment is essentially surgical. The results are however very variable as they depend on many factors, in particular the location, the evolutionary stage of the cyst and the operating technique used.

\section{Materials AND Methods}

This was a retrospective study of 40 medical reports, collected over a period of two years (between January 2017 and December 2018) at the AR-RAZI hospital radiology department of the Mohammed VI university hospital center in Marrakech in Morocco. Our patients underwent a standard first radiography followed by a chest scanner without and with the contrast medium injection. The aim of this study is to discuss the most frequent locations, with an iconographic review of their radiological aspects.

\section{RESULTS}

During the study period, we identified in our center, 40 cases of thoracic hydatid cysts in different locations. The average age of our patients was 37 years, predominantly male: 15 men and 25 women with a sex ratio of 1.6.

Our results reveal a predominance of rural origin with $60 \%$ of patients against $22 \%$ of urban origin. Note that in $18 \%$ of the cases, the origin had not been noted.

A notion of contact with dogs was found in $75 \%$. The history of hydatid cyst was found in $17 \%$. The functional signs were in the majority of cases relating to respiratory manifestations. They were predominant by cough, chest pain, dyspnea, hemoptysis or hydatidoptysis. They were found in 33 patients. It should be noted that a patient had consulted for a 
parietal mass without any other associated signs. General nonspecific signs such as fever sweat and worsening of the general statewere observed in 25 patients.

The discovery of hydatid cysts was fortuitous in 2 patients and this during a chest $\mathrm{x}$-ray for the prerecruitment medical examination and a thoracoabdomino-pelvic CT scan for breast cancer.
The radiological exploration was carried out in all our patients, the standard radiography requested in first intention was carried out in 30 cases, the chest CT scan without and with the contrast medium injection was performed on all of our patients, and MRI in 2 patients. The imaging results are shown in Tables 1 and 2.

Table-1: Results of radiological examination.

\begin{tabular}{|l|l|l|}
\hline Results & Cases & Percentage \% \\
\hline $\begin{array}{l}\text { Simple pulmonary hydatid cyst: } \mathrm{n}=12 \\
\text { single: } 8\end{array}$ & 22 & 55 \\
$\begin{array}{l}\text { Multiple: } 4 \\
\text { Complicated pulmonary hydatid cyst: } \mathrm{n}=10 \\
\begin{array}{l}\text { Ruptured in the bronchus }: \mathrm{n}=6 \\
\text { Ruptured in the pleural cavity }: \mathrm{n}=2 \\
\text { Cracked hydatid cyst: } \mathrm{n}=2\end{array}\end{array}$ & \\
\hline Pleura hydatid cyst & & \\
\hline Cardiac hydatid cyst & 4 & 10 \\
\hline Parietal hydatid cyst & 4 & 10 \\
\hline Mediastinal hydatid cyst & 2 & 5 \\
\hline Vertébro-spinal hydatid cyst & 6 & 15 \\
\hline
\end{tabular}

Table-2: Different location of thoracic hydatid cyst

\begin{tabular}{|l|l|l|}
\hline Organ & Location & Percentage \\
\hline Pulmonary & Right lower lobe $=10$ & 46 \\
& Medium lobe = & 11 \\
& Right upper lobe =1 & 6 \\
& Left upper lobe=0 & 0 \\
& Left lower lobe = 5 & 27 \\
\hline Parietal & Pectoral muscle =1 & \\
& Paravertebral muscle =1 & \\
\hline Cardiac & $\begin{array}{l}\text { Intra ventricular: } \mathrm{n}=1 \\
\text { pericardial =1 } \\
\text { the right atrium: } \mathrm{n}=1\end{array}$ \\
& pericardial and intra-auricular $\mathrm{n}=1$ & \\
\hline Mediastinal & All compartments & \\
\hline Vertébro-spinal & T2 to T5 and T12 & \\
\hline
\end{tabular}

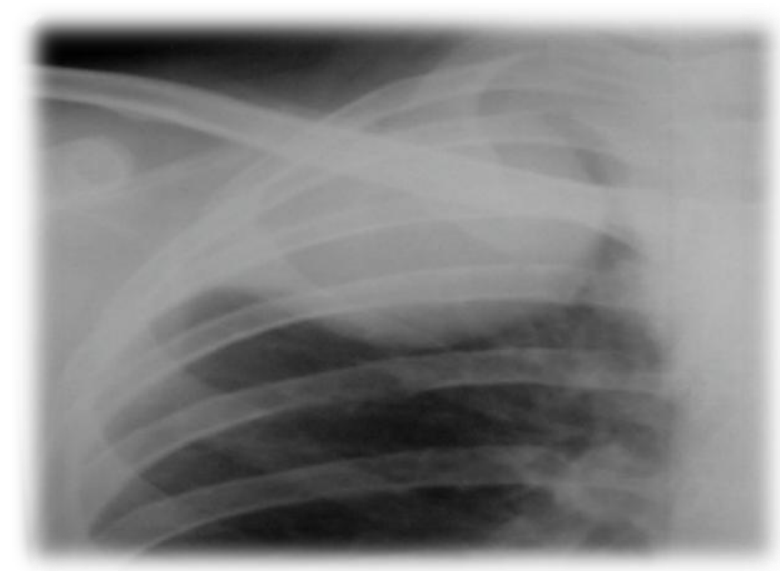

Fig-1: Opacity of water tone, in the right upper lobe, homogeneous, dense, single, with clear contours, rounded $\rightarrow$ simple pulmonary hydatid cyst

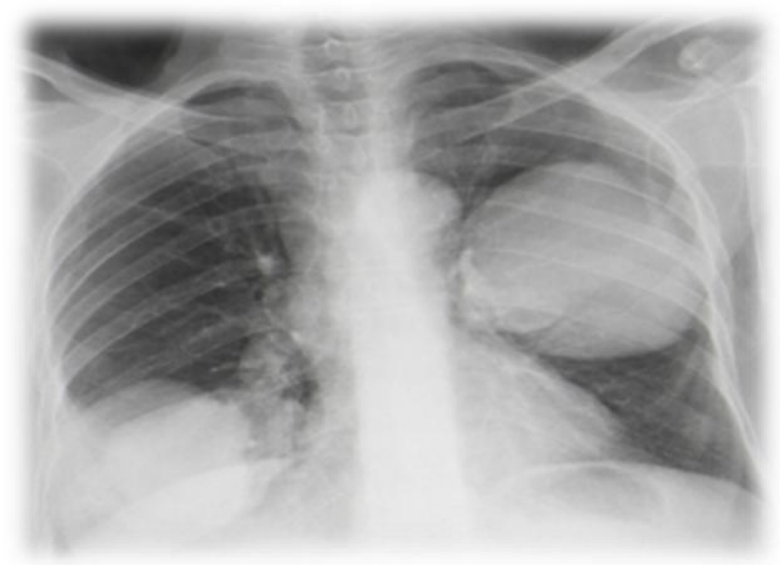

Fig-2: Multiple pulmonary opacity of water tone, homogeneous, dense, rounded $\rightarrow$ multiple pulmonary hydatid cyst 


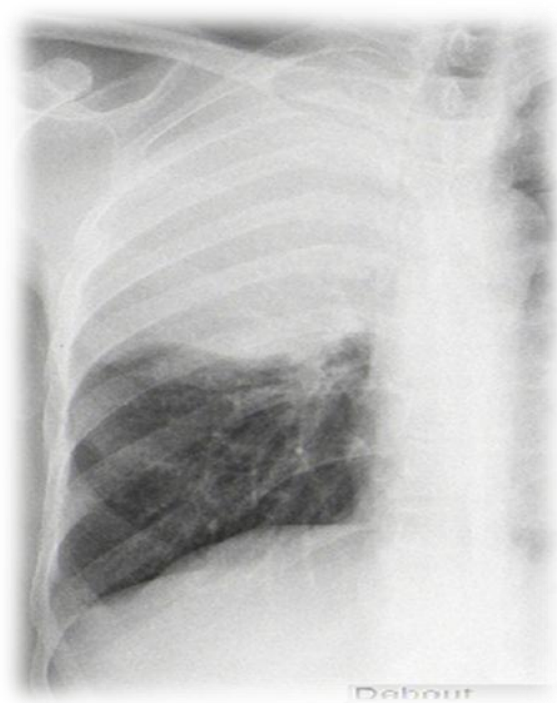

Fig-3: Right upper lobar fluid mass with well circumscribed thickened wall surrounded with perilesional condensation associated

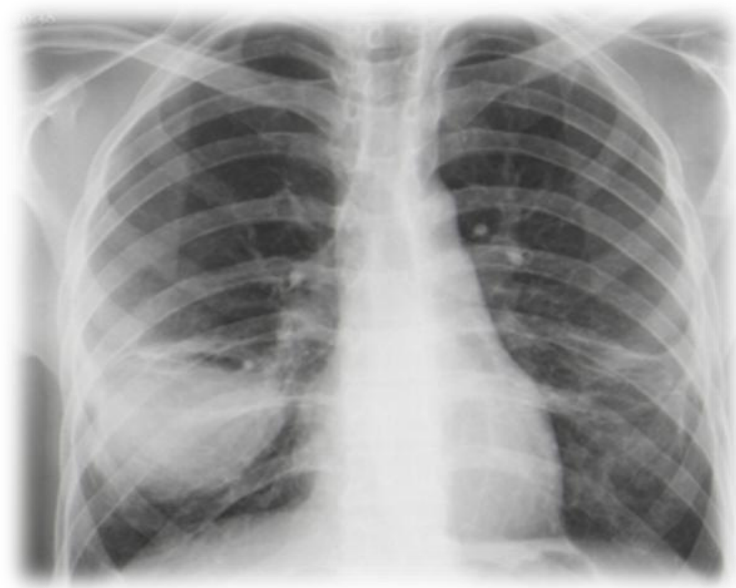

Fig-4: Right basal opacity, fairly limited, roughly rounded, dense, heterogeneous, appearing to be excavated $\rightarrow$ ruptured pulmonary hydatid cyst

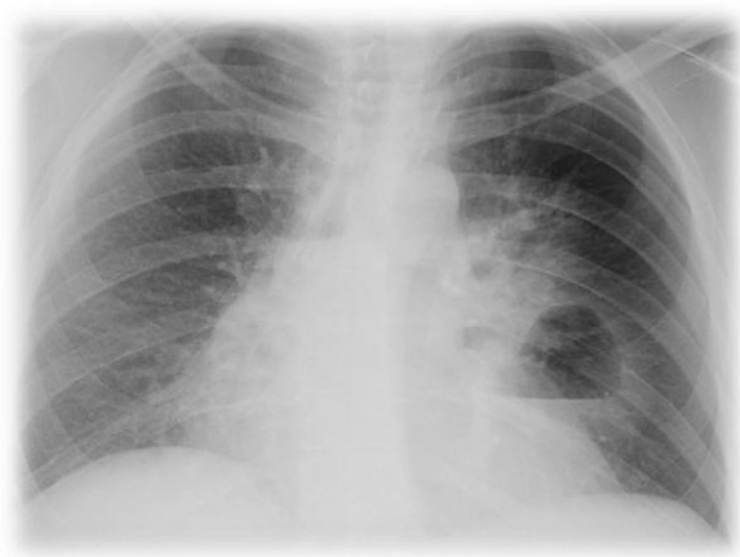

Fig-5: Left lower basal opacity, fairly limited, roughly rounded, heterogeneous, hydro-aerobic image with regular level $\rightarrow$ ruptured pulmonary hydatid cyst in the bronchia

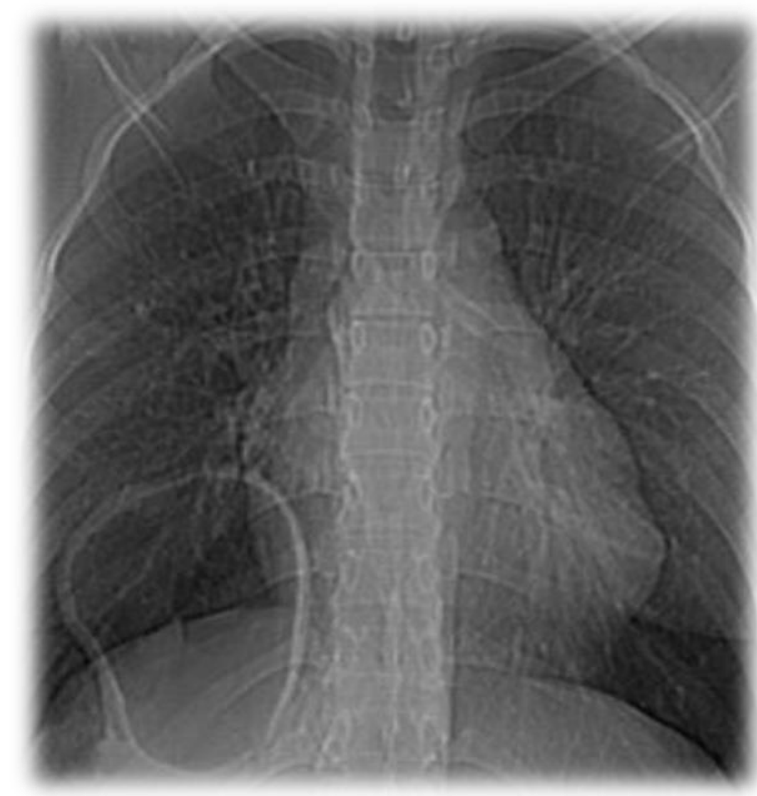

Fig-6: Right lower lobe cyst with thickened wall $\rightarrow$ ruptured pulmonary hydatid cyst in the bronchia
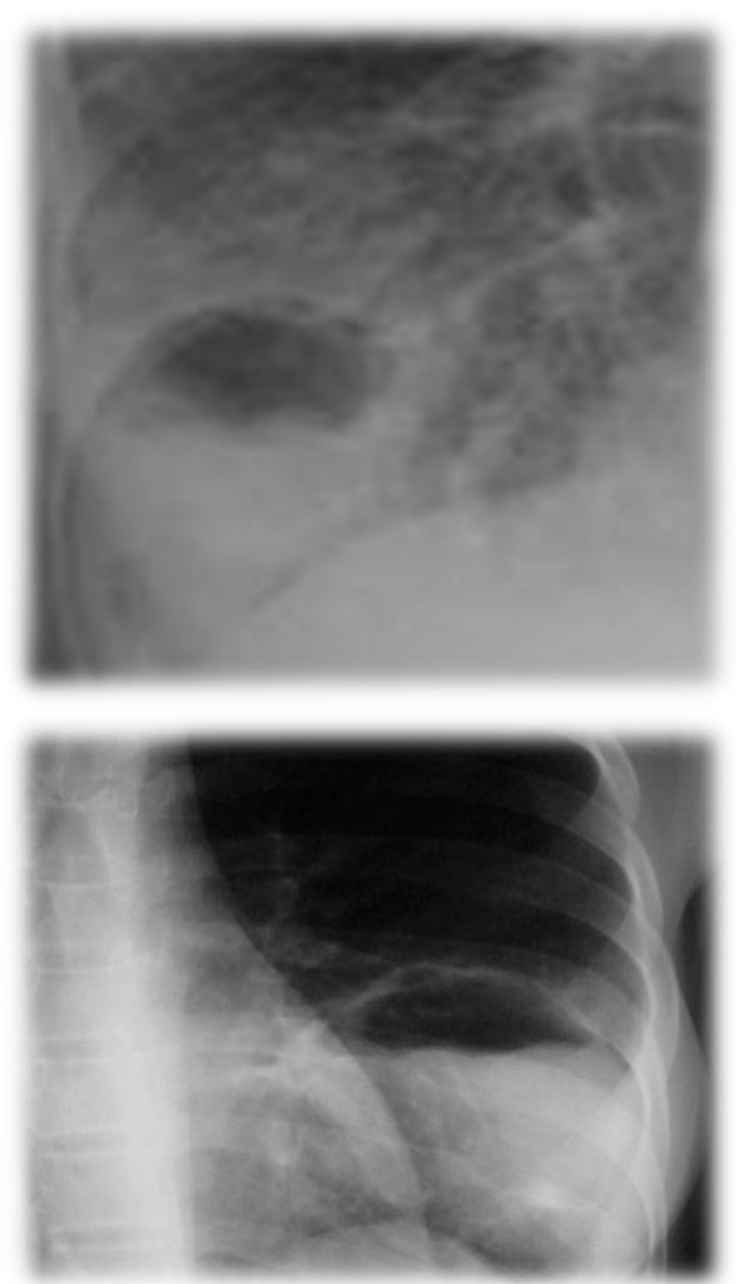

Fig-7: left lower basal opacity, fairly limited, roughly rounded, heterogeneous, hydro-aerobic image with irregular level (water lily sign) $\rightarrow$ ruptured pulmonary hydatid cyst in the bronchia 


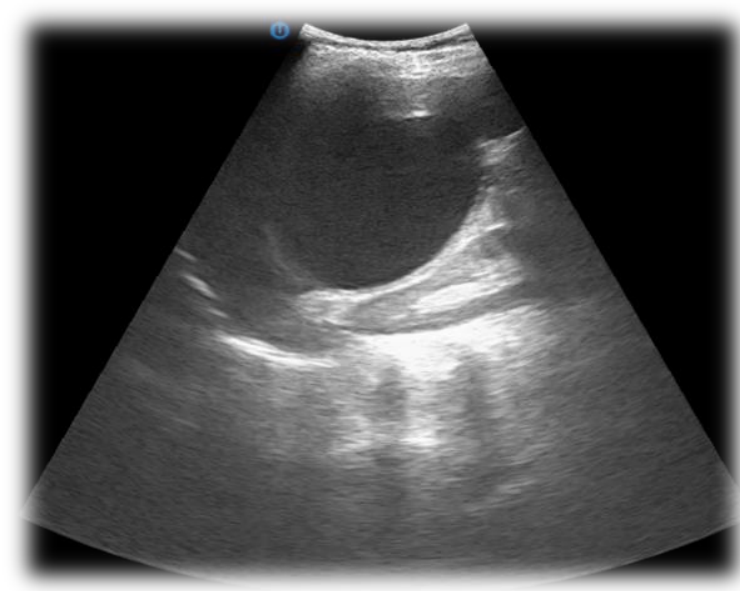

Fig-8: Right lower basal opacity, fairly limited, roughly rounded, heterogeneous, hydro-aerobic image with irregular level and aciform clarity that surrounds the part of the opacity (Ivassinevitch's double arc sign)

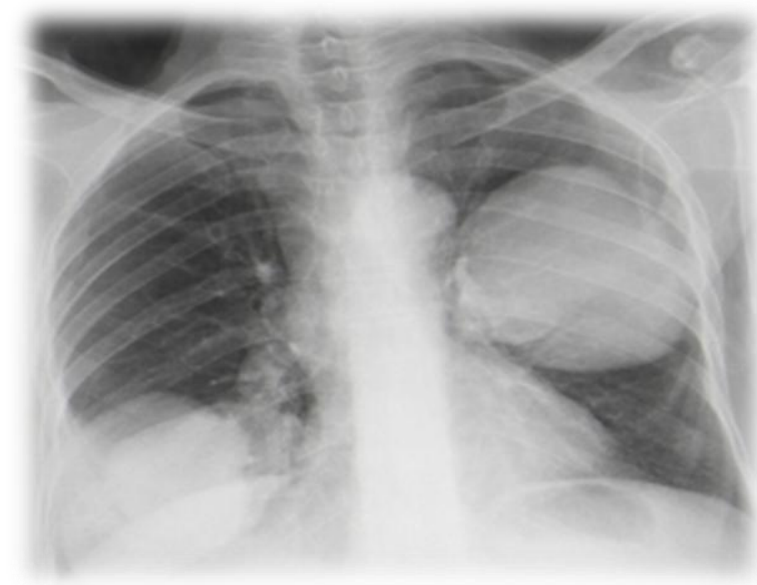

Fig-9: Right lower basal opacity, fairly limited, roughly rounded, dense, ultrasound complement: simple cyst right lower lobe

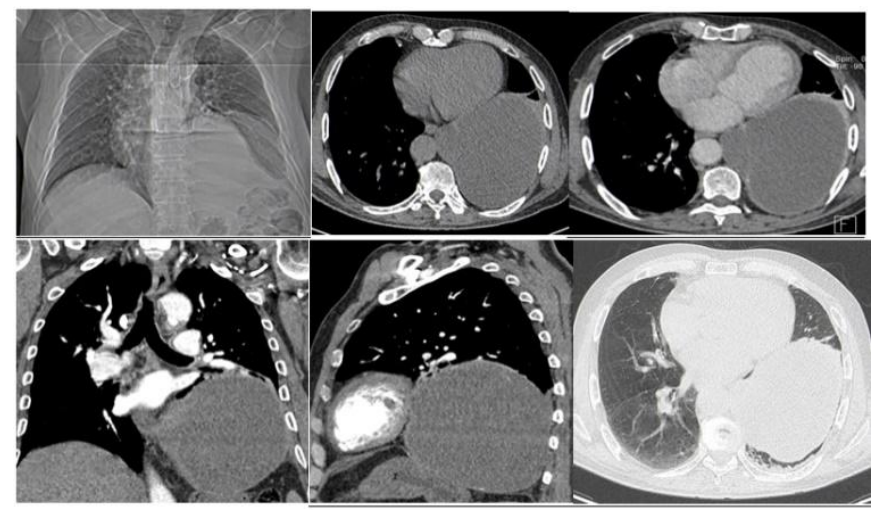

Fig-10: Left lower lobar cystic formation of roughly rounded shape, regular contours, thin and regular wall. It is spontaneously hypodense, not changed after injection of contrast medium

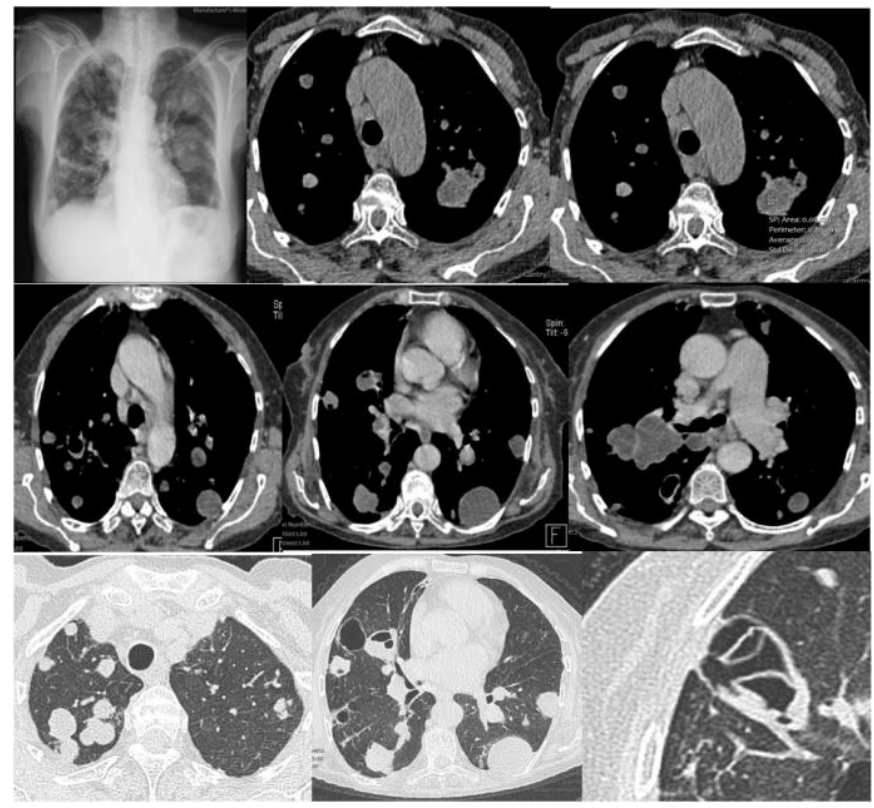

Fig-11: Multiple cystic formations scattered at the two pulmonary hemi-fields, of rounded form, with thin wall (discretely calcified for some), some of which are the seat of excavation with hydro-air levels and floating membranes => pulmonary hydatidosis looks like letting go of balloons. 

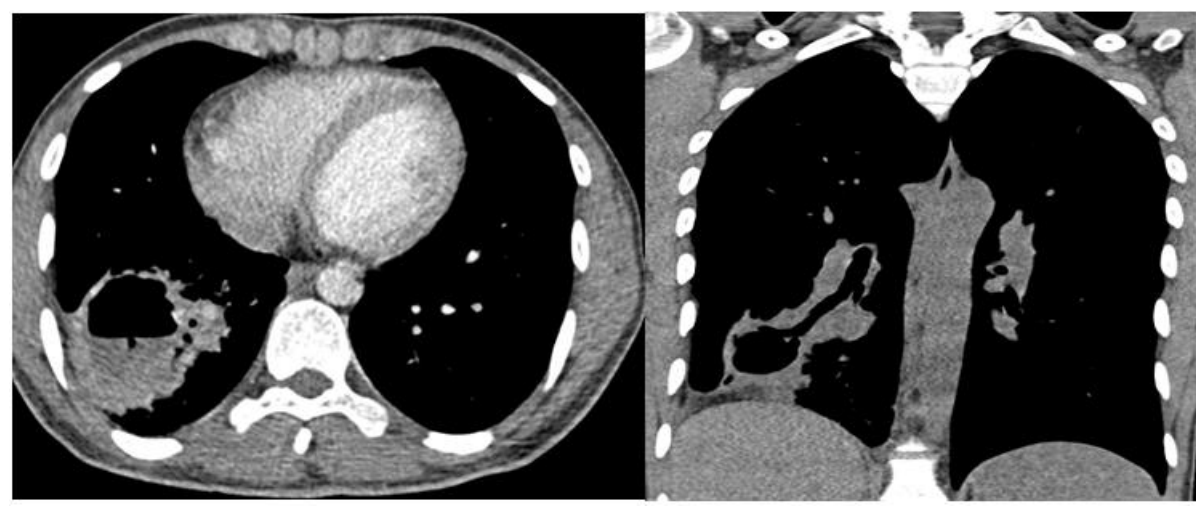

Fig-12: Ruptured pulmonary hydatid cyst in the bronchia
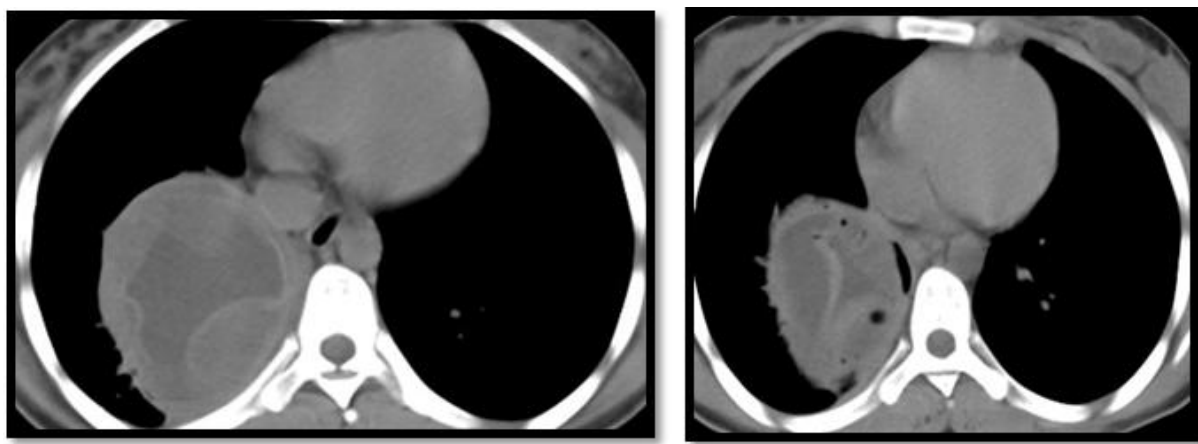

Fig-13: Rounded formation of the right lower lobe with water content with membrane detachment and intra cystic air bubbles $\rightarrow$ ruptured pulmonary hydatid cyst in the bronchia
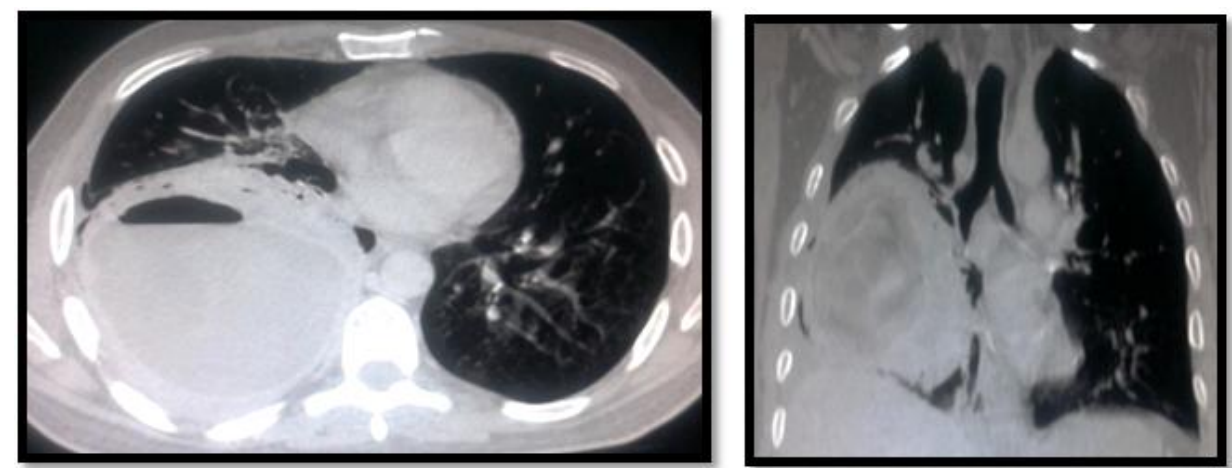

Fig-14: Rounded formation of the right lower lobe with water content with membrane detachment and intra and péricystic air bubbles $\rightarrow$ ruptured pulmonary hydatid cyst in the bronchia.
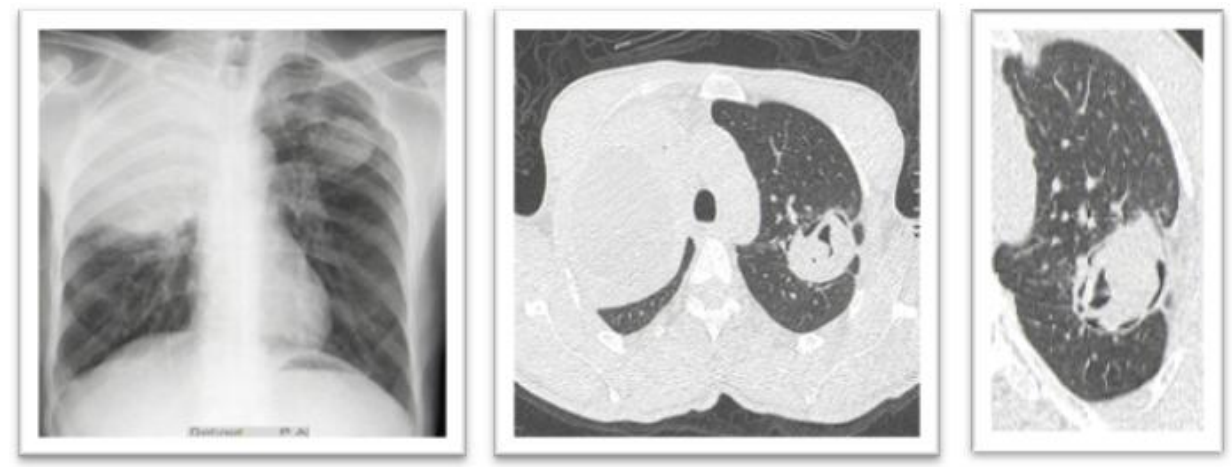

Fig-15: Right upper lobe fluid mass with well-circumscribed thickened wall surrounded with perilesional condensation associated second fluid mass with a water lily sign of the left upper lobe $\rightarrow$ ruptured pulmonary hydatid cyst in the bronchia. 

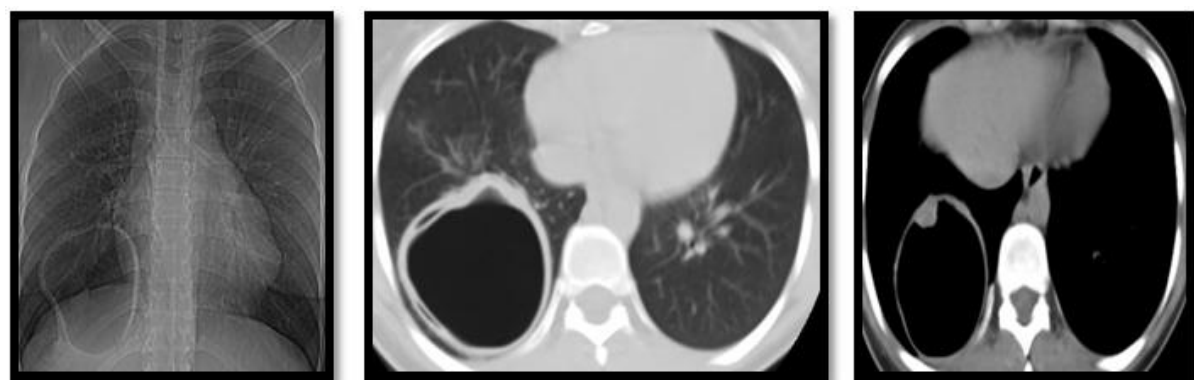

Fig-16: Rounded cavitary lesion of the right lower lobe with air content, slightly thickened wall, presenting an intracystic wall nodule and membrane detachment $\rightarrow$ Ruptured pulmonary hydatid cyst in the bronchia.
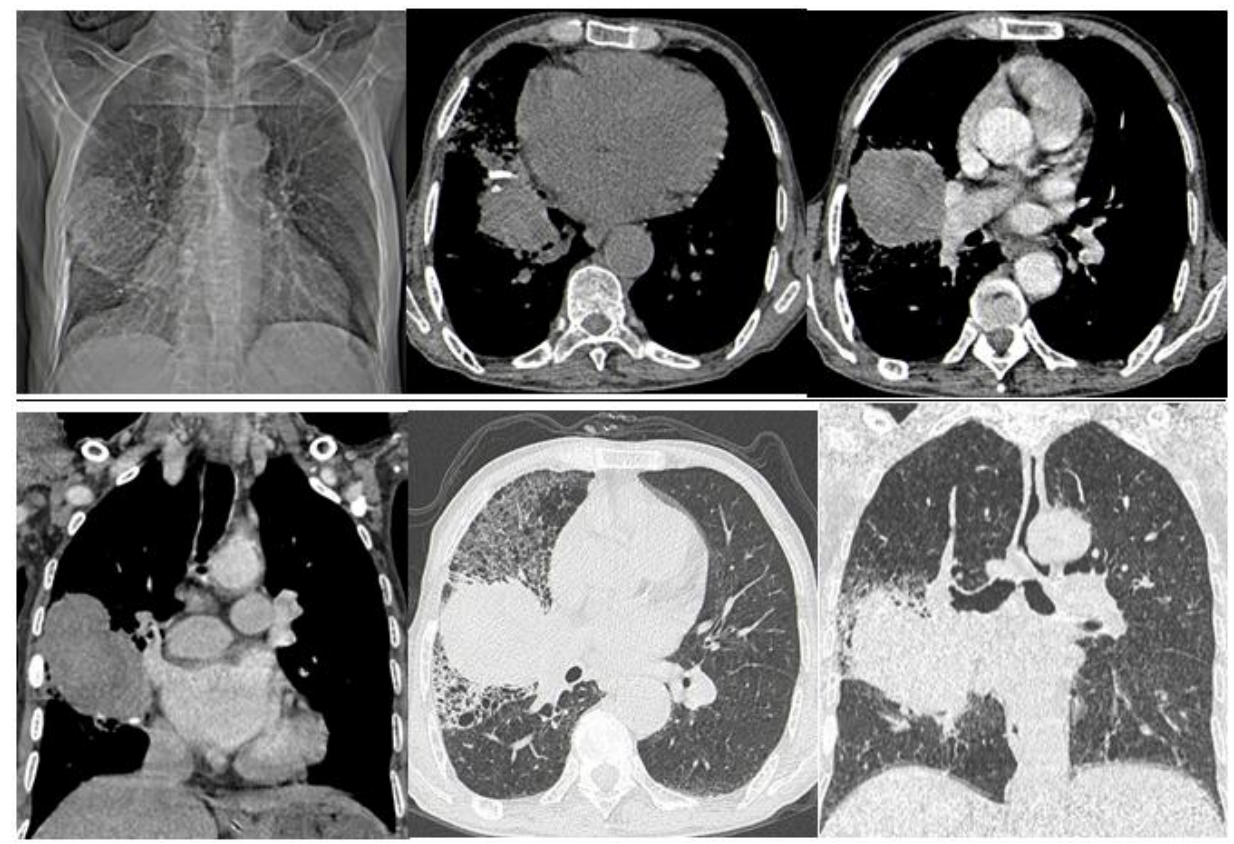

Fig-17: intra-parenchymal lesion of middle lobe, irregular contours, heterogeneous non-elevated after injection of contrast medium, seat of parietal calcification, associated with a neighboring reticular infiltrate (Loeffler's syndrome). Ultra-sonographic complement: heterogeneous anechoic lesion, seat of septa, non-vascularized with color Doppler in favor of hydatid cyst

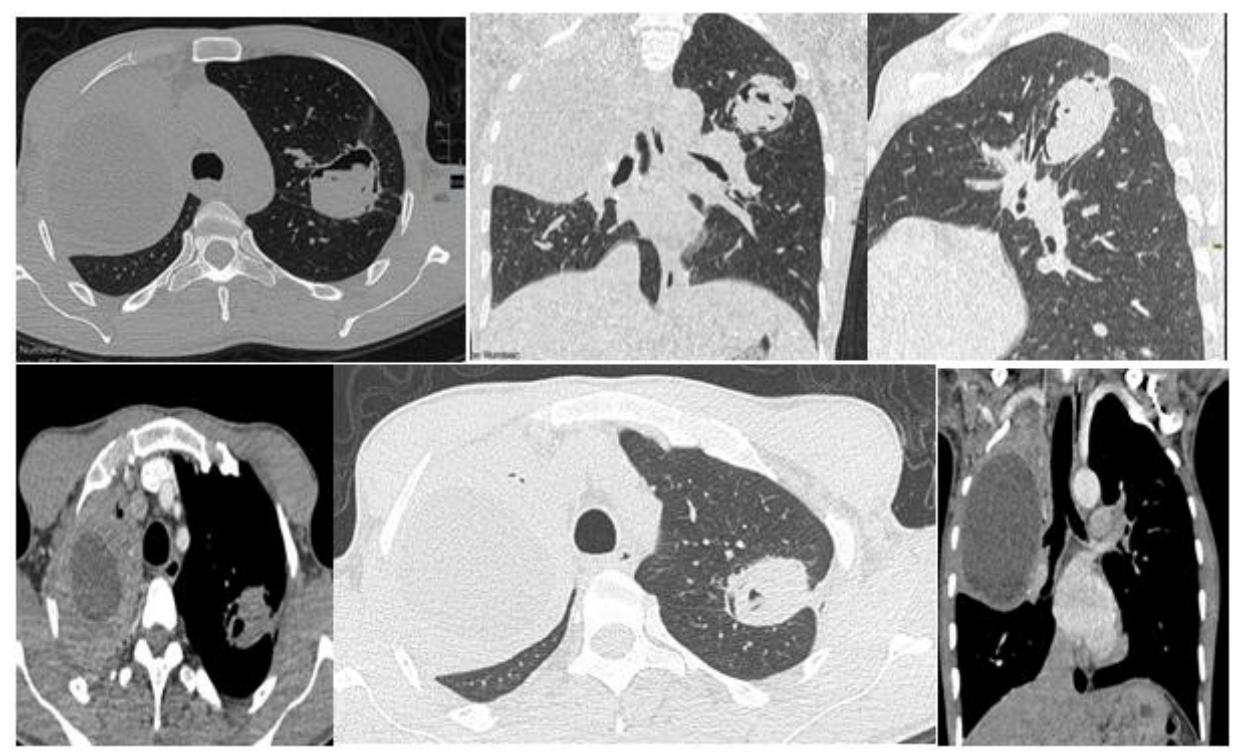

Figure 18: left apical cystic formation communicating with the neighboring bronchi, it comes into contact and communicate with the pleura, which is the seat of cystic formations with hydro-aeric levels $\rightarrow$ Ruptured pulmonary hydatid cyst in the pleura and the bronchia 

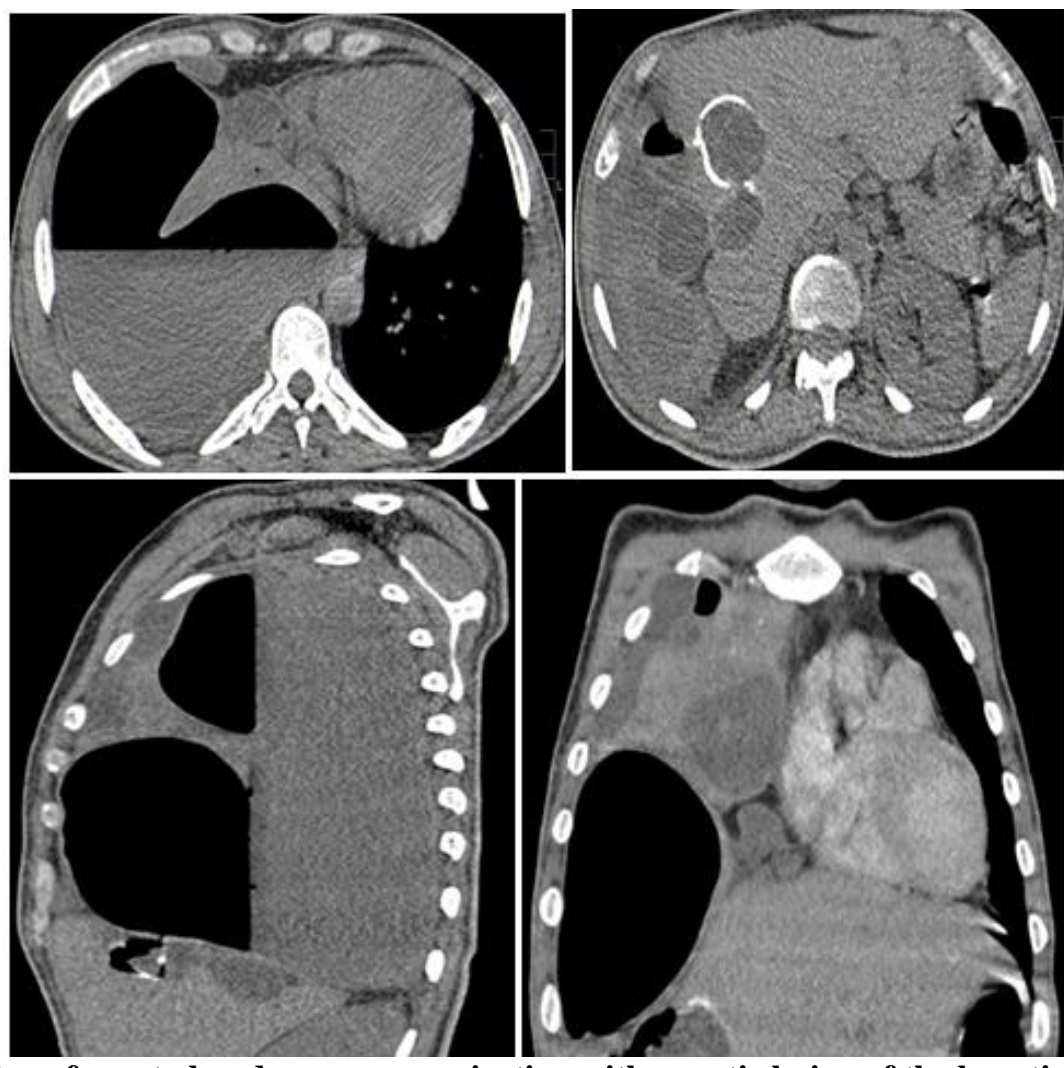

Fig-19: Pleural effusion of great abundance communicating with a cystic lesion of the hepatic domeassociated with mediastinal and inter hepato-diaphragmatic lesions $\rightarrow$ hydatid origins.

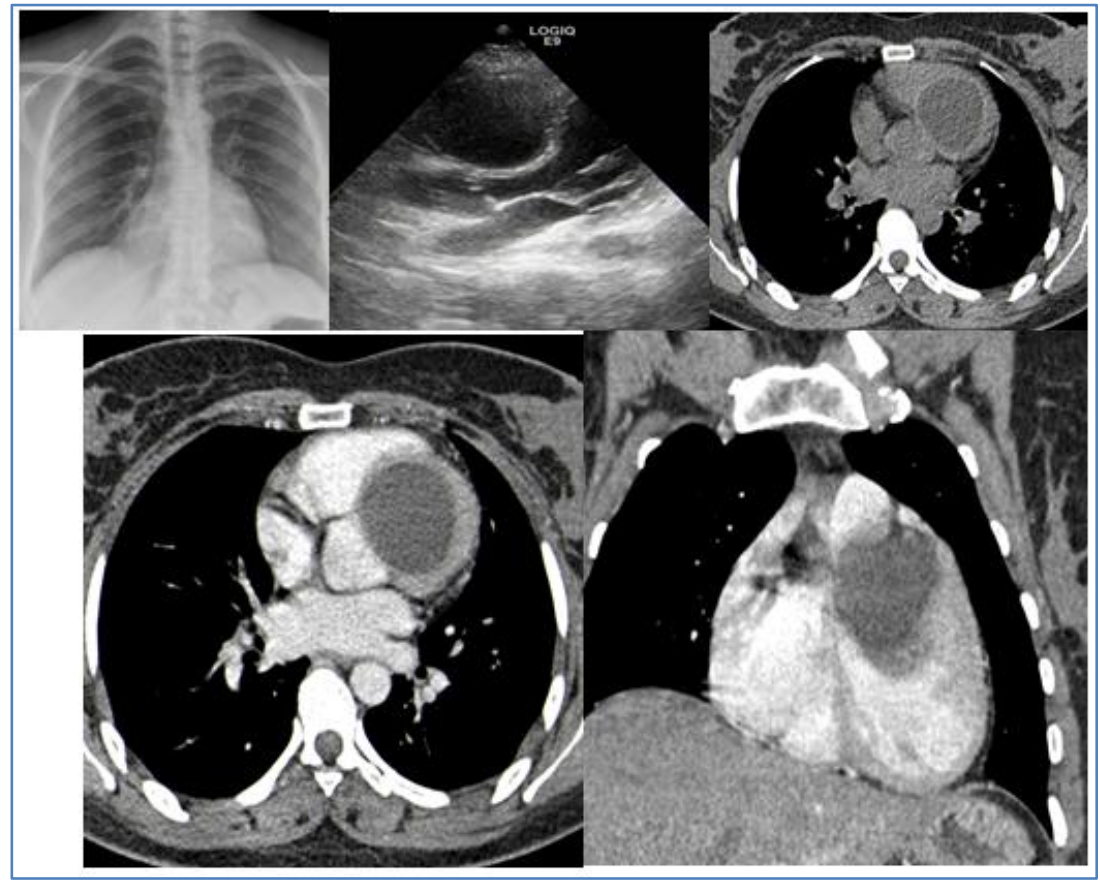

Fig-20: Left ventricular cystic formation, rounded, with pure fluid content, thin walled, not changed after injection of contrast material, related to an intra ventricular hydatid cyst 


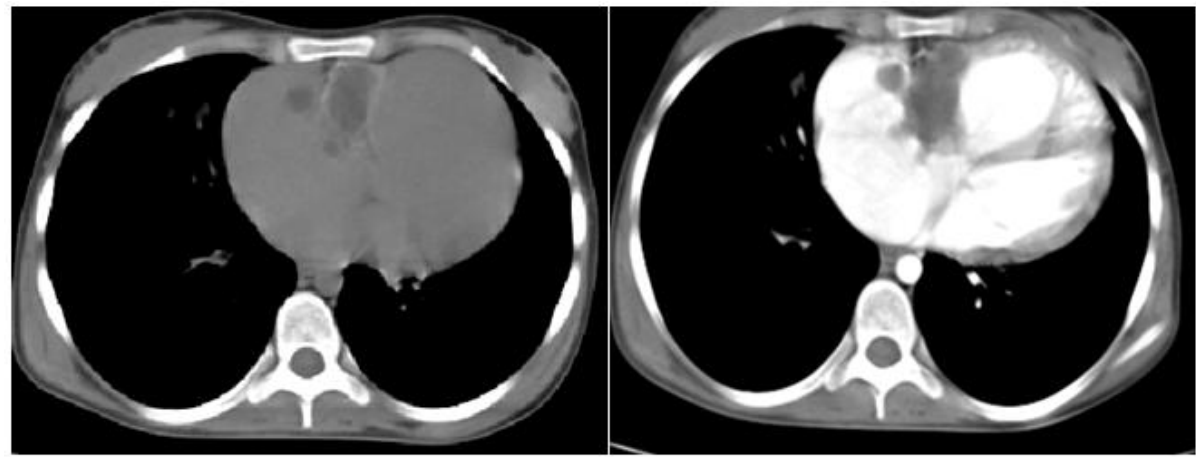

Fig-21: Tricuspid cystformation in favor of a hydatid cyst
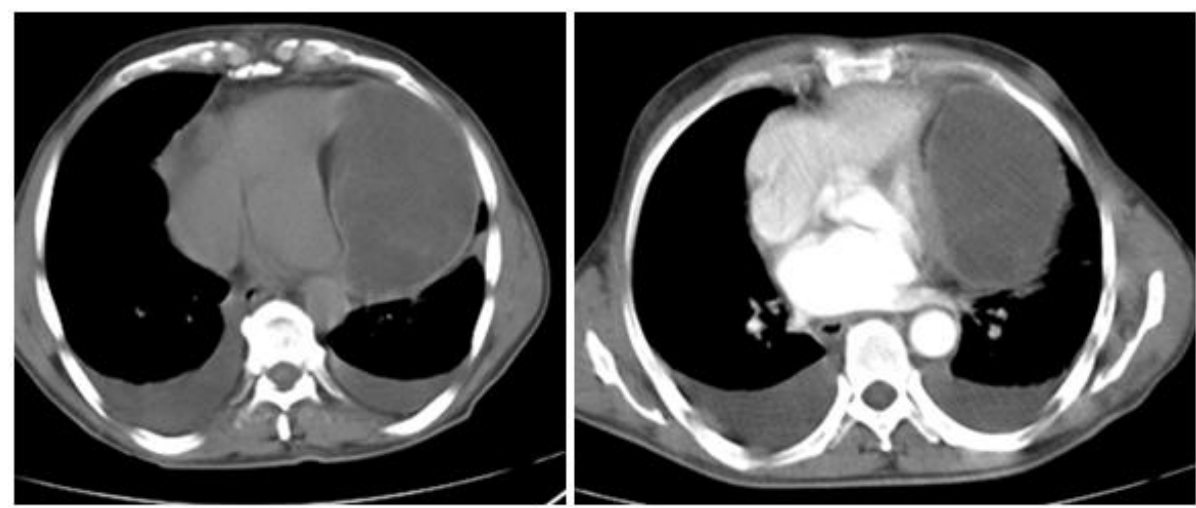

Fig-22: Pericardia cystic formation, rounded, with pure fluid content, thin walled, not changed after injection of contrast material, related to pericardia hydatid cyst.

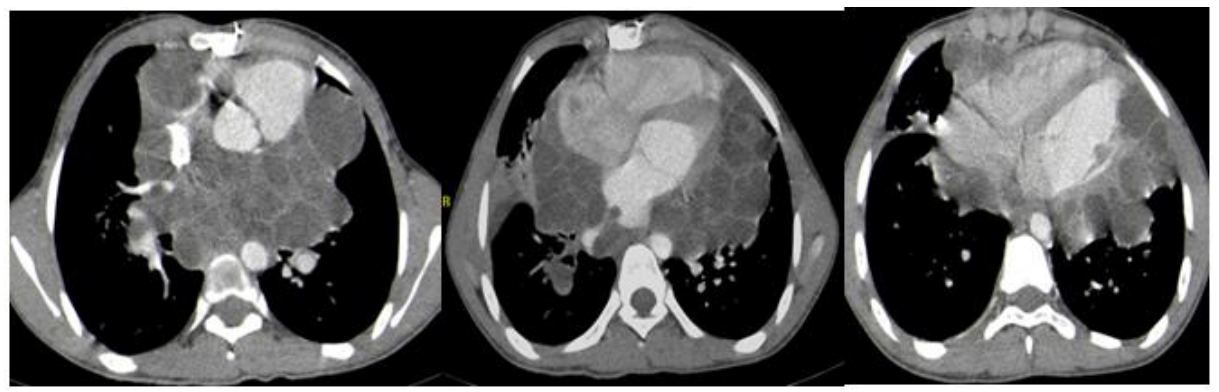

Fig-23: Hydatid cystic in the mediastinal compartments, with bilateral pericardial and intra-auricular localization, of variable size, rounded, with pure fluid content, thin walled not changed after injection of contrast medium.

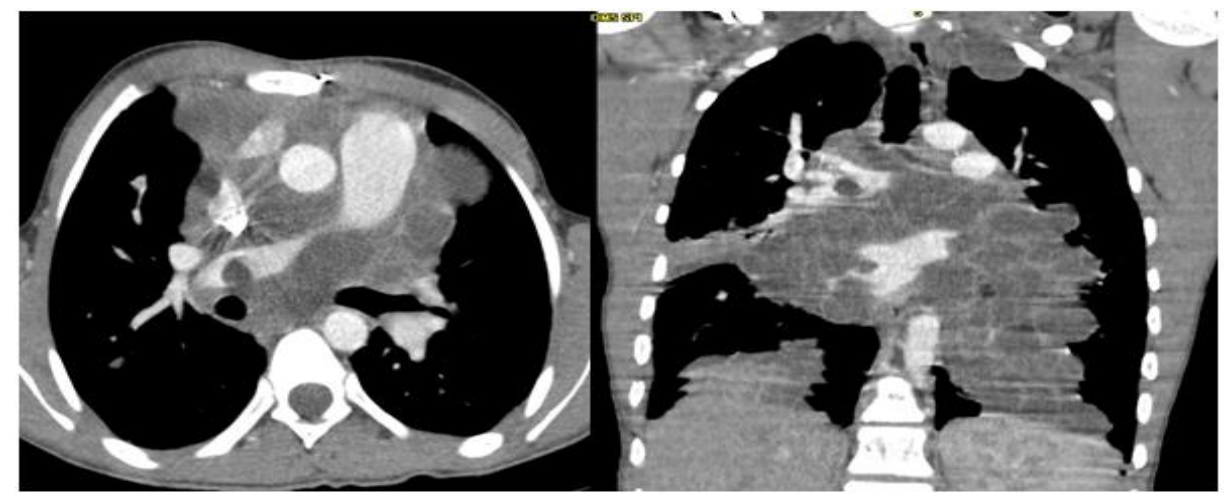

Fig-24: Hydatid cystic in the mediastinal compartments, with cardiac and pulmonary artery localization, of variable size, rounded, with pure fluid content, thin walled, not changed after injection of contrast material. 


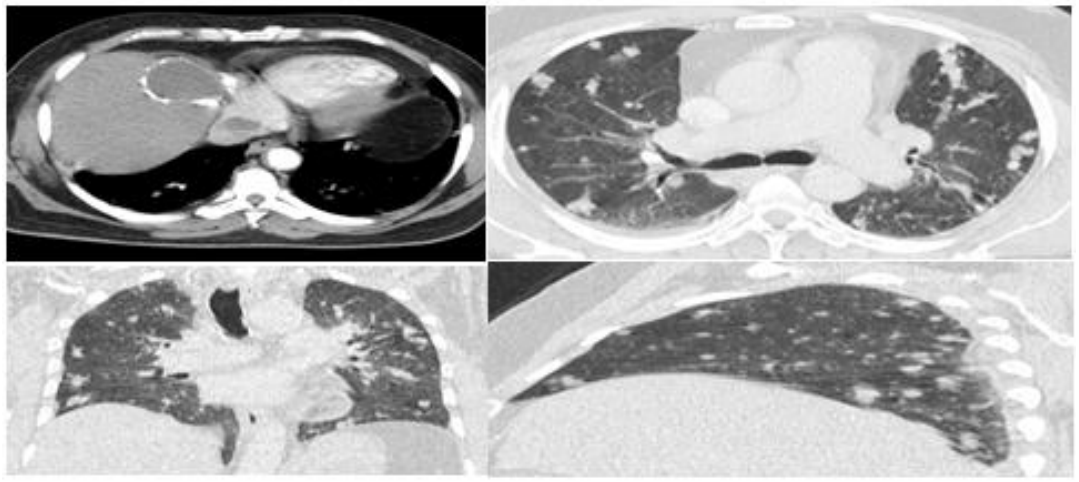

Fig-25: A: Two cystic formations in segment VIII of the liver and right atrium related to hydatid cysts. B,C,D: multiple nodules scattered in the two pulmonary hemi-fields related to hydatid septic emboli
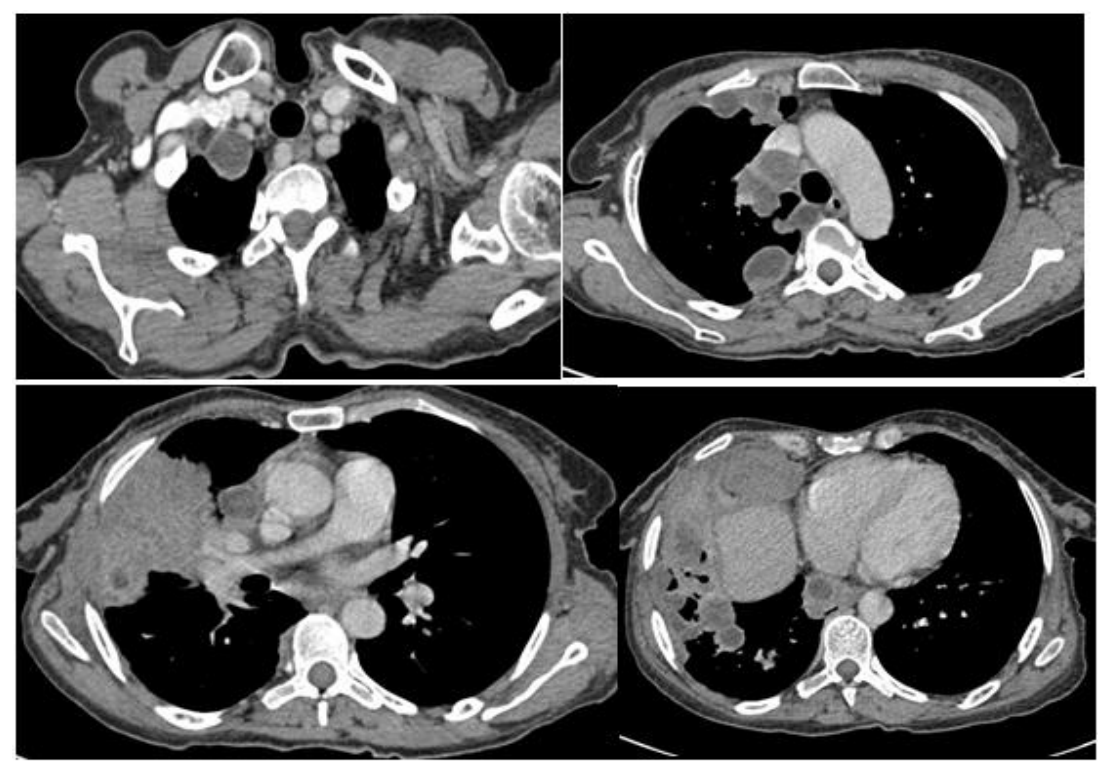

Fig-26: Hydatid cystic in the mediastinal compartments, with pulmonary localization, of variable size, rounded, with pure fluid content, thin walled not changed after injection of contrast medium.

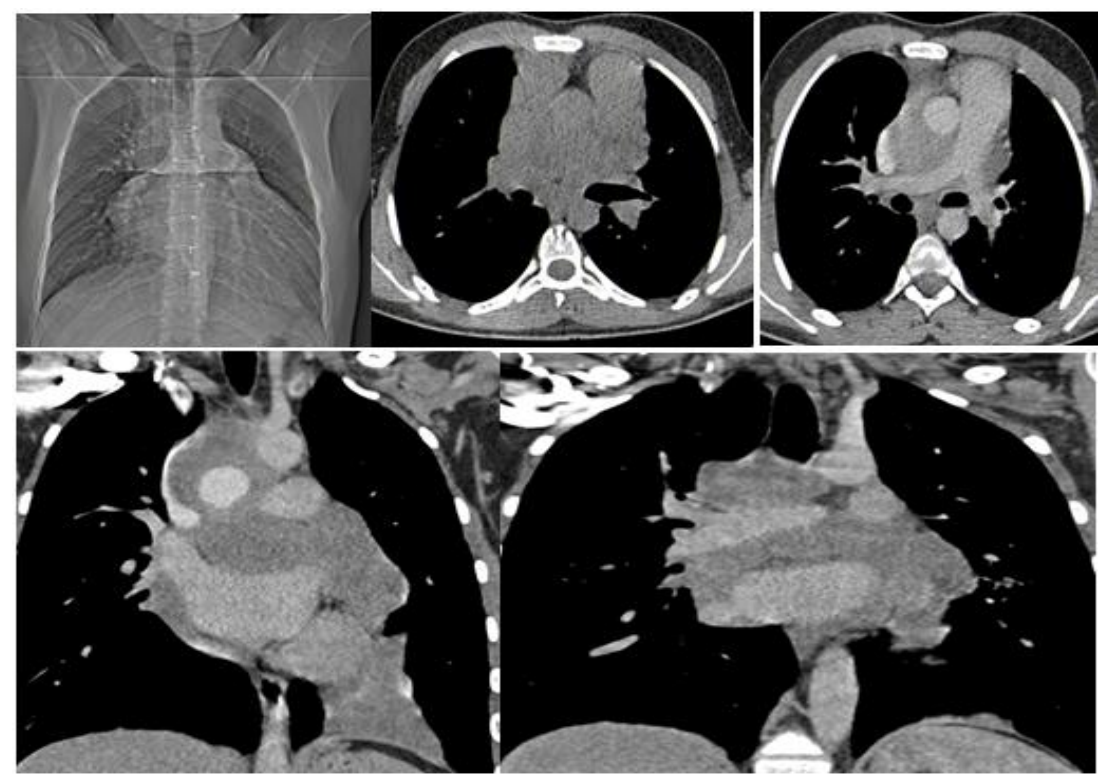

Fig-27: Initial CT: Large mediastinal hypodense formation of interest to Barety's lodge, pre- and subcarinal space and anterior mediastinum, extended to pericardium and right atrium, not changed afterinjection. Responsible for the compression of superior vena cava and right pulmonary artery with reduced diameter as well as the cardiac cavities 

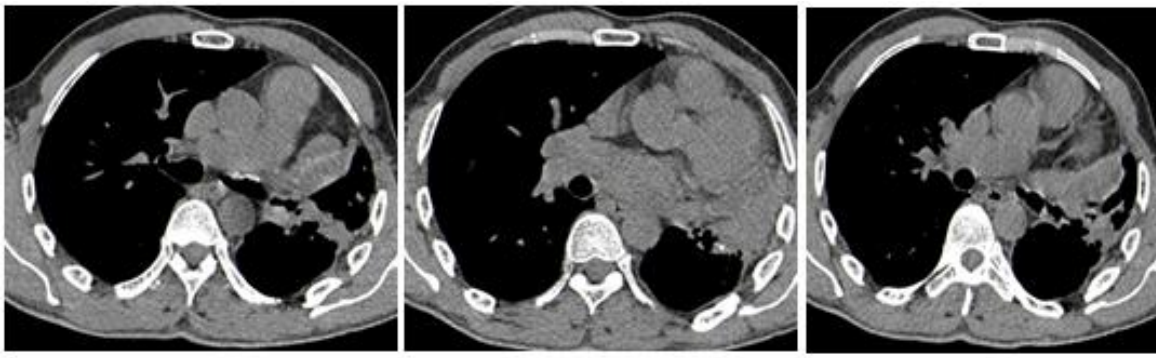

Fig-28: Control CT one year after medical and surgical treatment
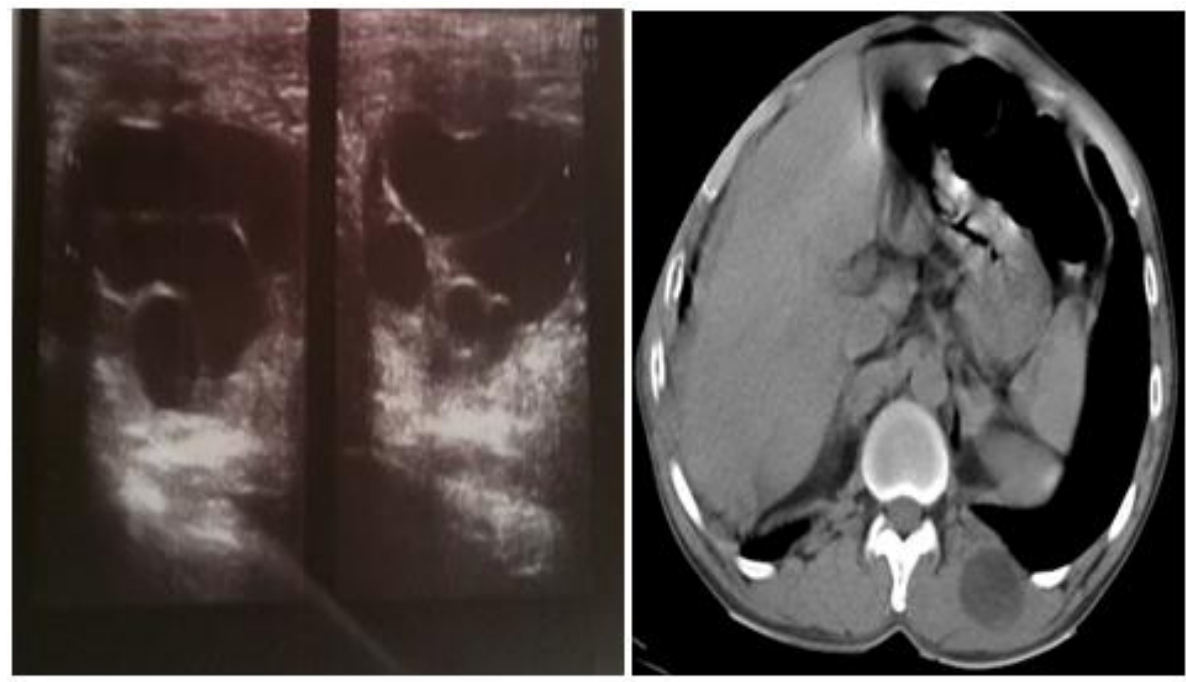

Fig-29: Cyst formation in paravertebral muscle related to hydatid cyst
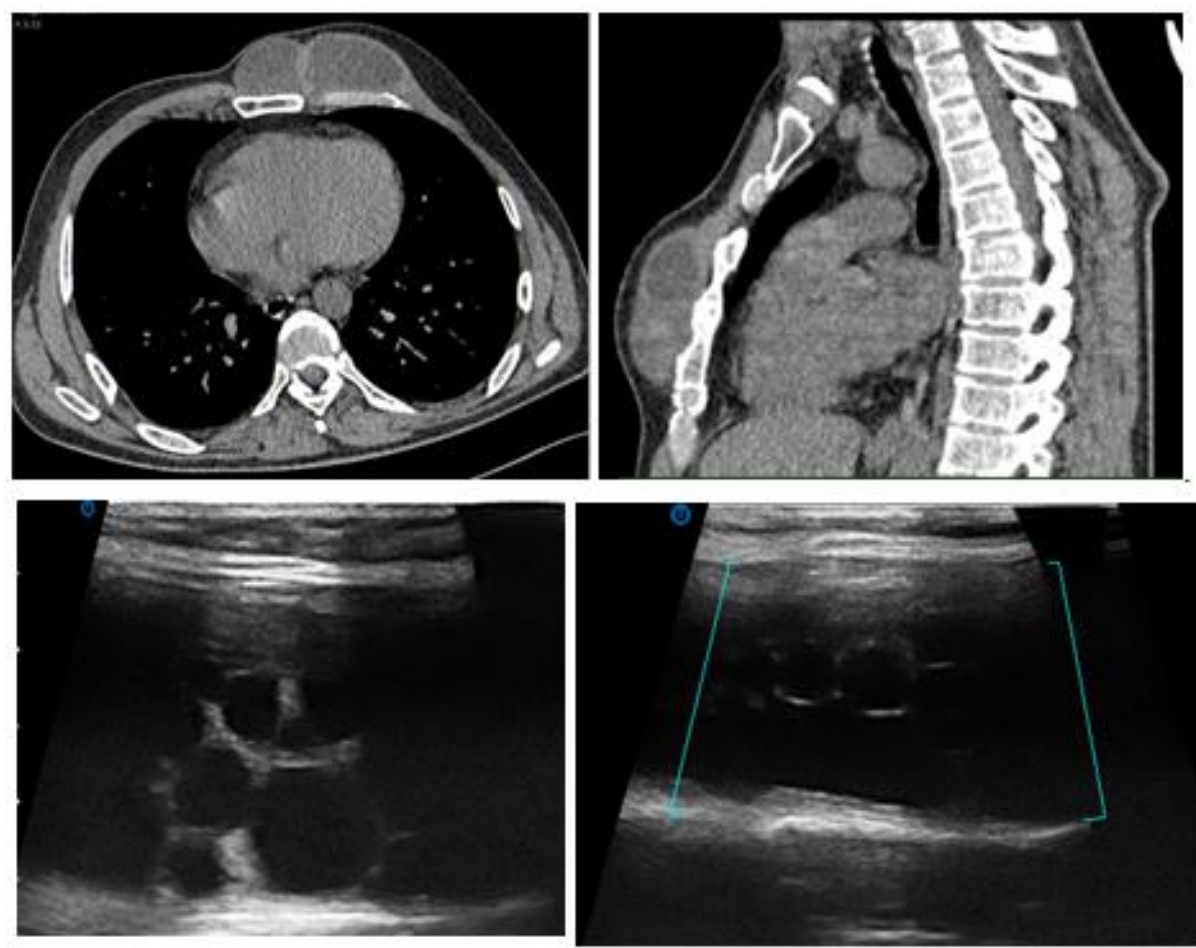

Fig-30: Two subcutaneous cystic formations, contiguous at left pectoralis major muscle, without costal or endothoracic extention related to hydatid cyst, US: Cystic formation subcutaneous multi-locating, coming into contact with the left pectoralis major muscle, not lighting up with the color Doppler $=>$ hydatid cyst of the pectoralis major. 


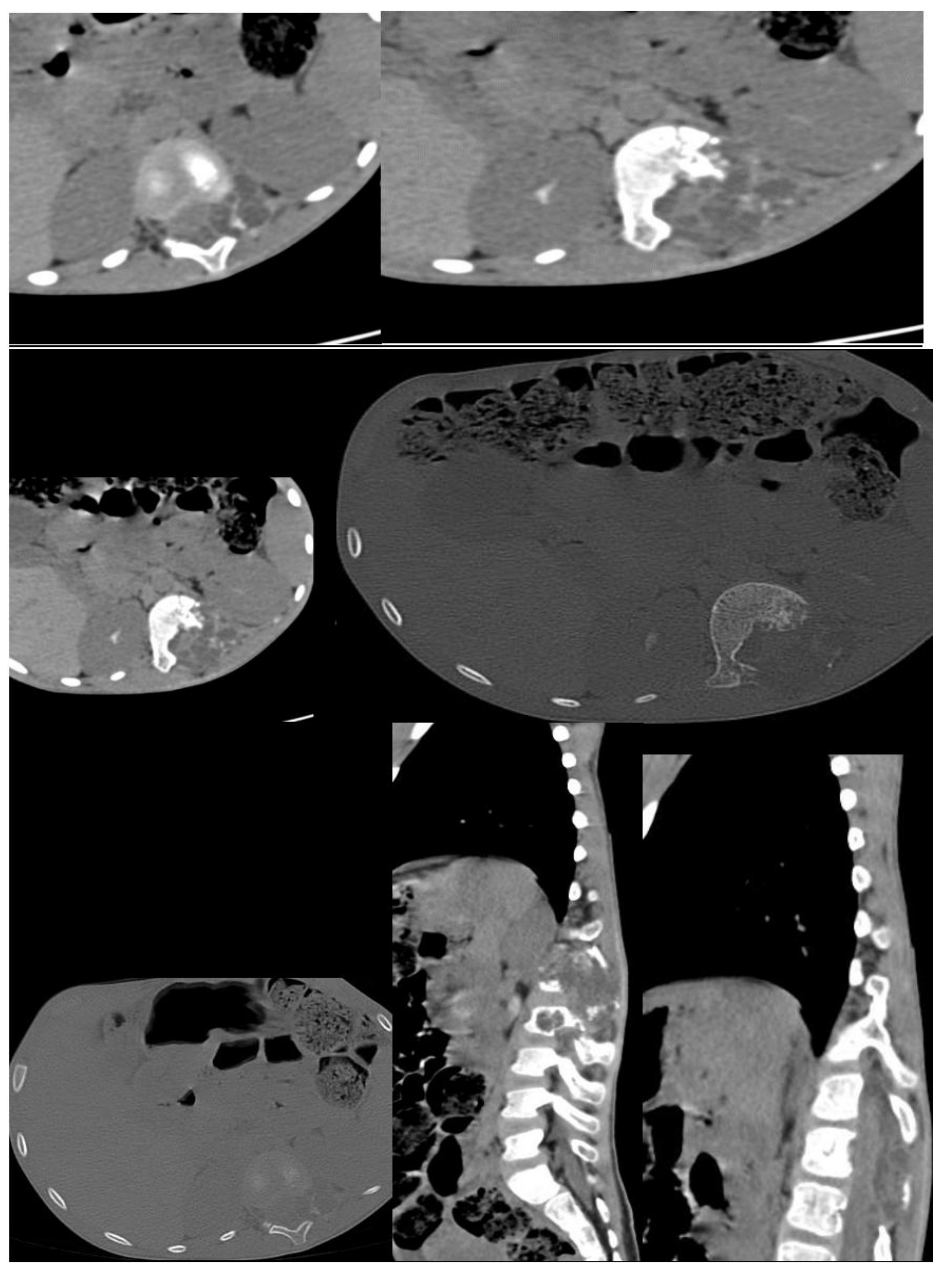

Fig-31: Multiple cystic formations responsible for lysis of the vertebral bodies, transverse processes, pedicles and lamina extended from $\mathrm{T} 12$ to $\mathrm{L4}$

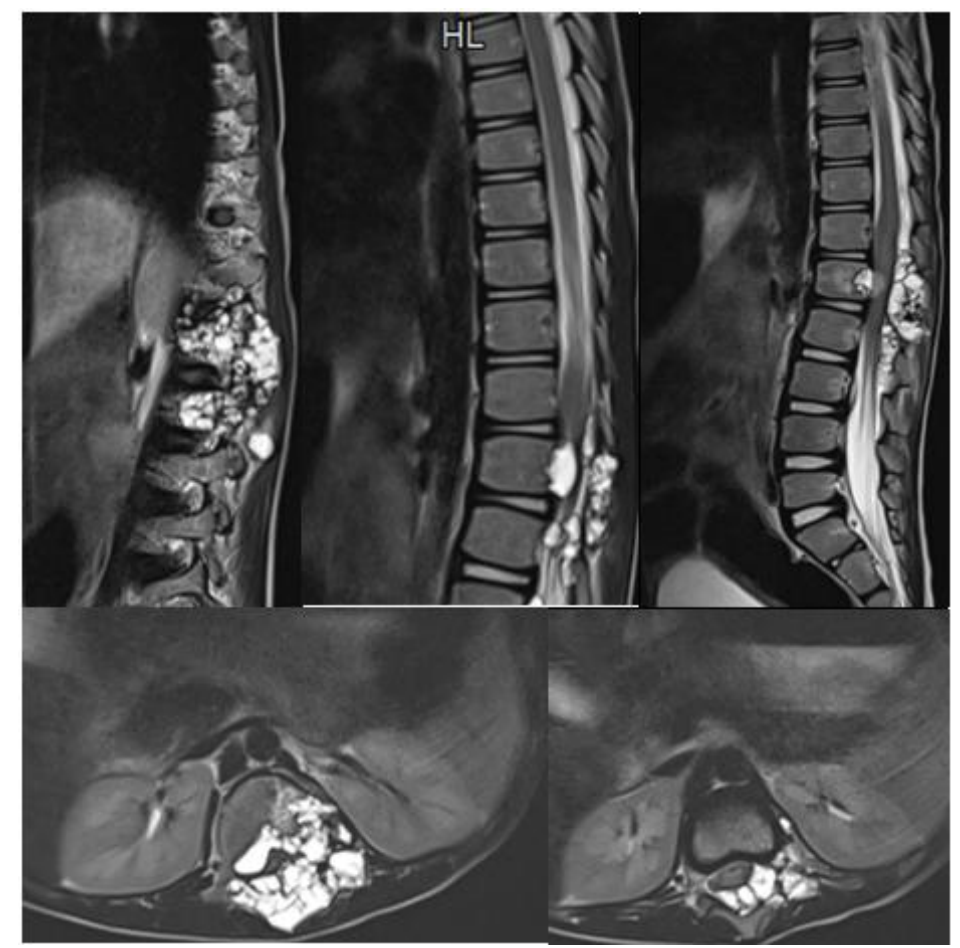

Fig-32: expansive multilocular cystic formations in the anterior and posterior epidural spaces and the left middle and posterior arches extended from $\mathrm{T} 12$ to L4hyperintense T2 


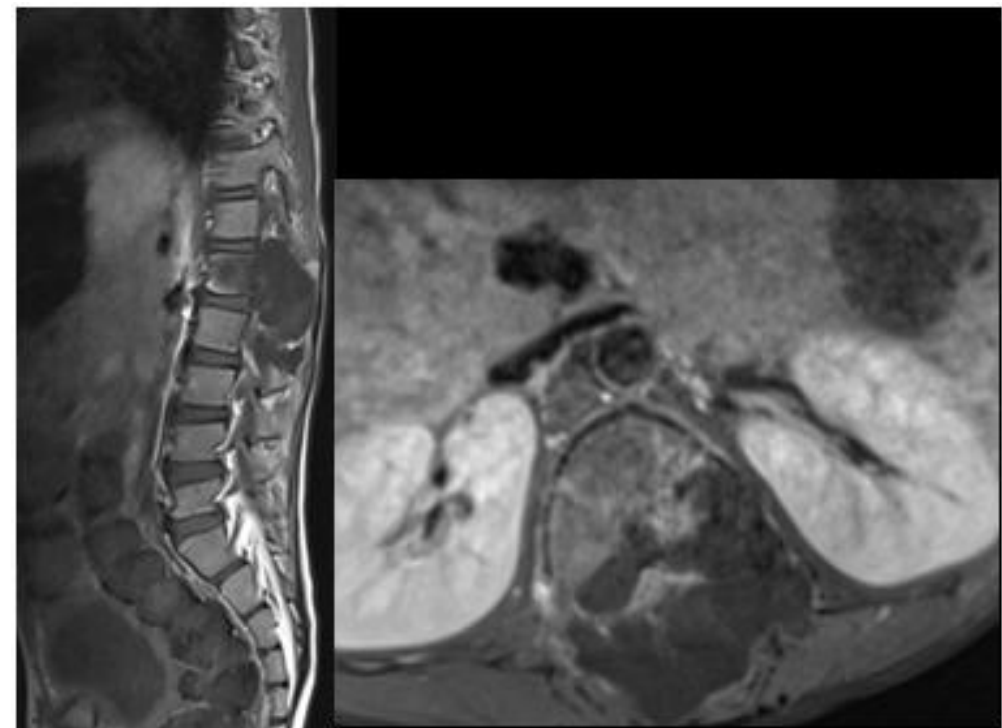

Fig-33: Expansive multilocular cystic formations in the anterior and posterior epidural spaces and the left middle and posterior arches extended from T12 to L4 hypo intense T1.

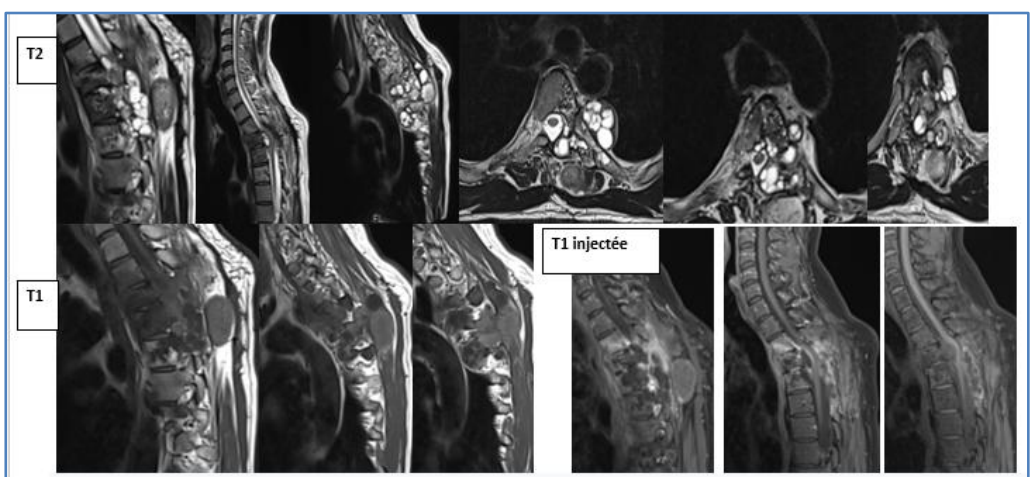

Fig-34: multiple intracutal, intra-dural extra-medullary cystic formations, in height from T2 to T5; These cystic formations are multi-vesicular, some are homogeneous in fluid content, with $\mathrm{T} 1$ hypointense and $\mathrm{T} 2$ hyperintense, others are heterogeneous and enhanced at the periphery after injection of Gadolinium.

\section{DISCUSSION}

The hydatid cyst is a parasitosis that is still rampant in the endemic state in our country. It can affect all thoracic compartments and is dominated by pulmonary involvement. Its diagnosis is essentially radio-clinical. The imagery remains primarily based on chest radiography, thoracic ultrasound is useful in peripheral pulmonary, pleural, parietal, cardiac and mediastinal localizations. CT is often necessary to confirm the cystic nature of chest opacity, but also to clarify the location of the cyst, study its reports and assess the state of the host parenchyma.

\section{1) Pulmonary hydatid cyst}

The lung is the most frequently affected organ after the liver, which is the primary filter. Preferential involvement of the right lung is classic in the literature and the frequency of bilateral pulmonary hydatidosis can vary from 3 to $26 \%$ or even $38 \%$ in certain endemic regions [1]. Its preferred location is the pulmonary bases, essentially on the right with $36.5 \%$ of the right lower lobe affected, It underlined in our study. This predominance of location in the lung bases is probably explained by the increased blood flow to the lung bases [2].

For most authors [3, 4], the predominance of men seems classic because of the professions exposed, the young adult under 30 , is reached in $70 \%$ of cases [3].It underlined in our study.

The discovery can be accidental, when it is asymptomatic. The pulmonary hydatid cyst can be revealed by non-specific respiratory signs; such as chest pain, dyspnea, cough, hemoptysis and / or hydatidoptysis, which is the most evocative symptom. This is defined by the rejection during a coughing effort of a rock water liquid containing pearly white membranes. Infectious signs may be associated with disinfection of the cyst. Allergic manifestations are exceptional. The clinical examination is poor, large cysts can mimic a fluid effusion syndrome. We have to look for other associated locations. 


\section{a) Chest x-ray}

The radiological expression of the pulmonary hydatid cyst is very varied. Simple pulmonary hydatid cyst results in an opacity of water tone, homogeneous, dense, single (Fig 1) or multiple (Fig 2), with clear contours, rounded or oval, in "cannon ball" or "rugby ball" very suggestive of the diagnosis. Sometimes the limits of opacity are blurred, (Fig. 3), witness of a reaction of the pulmonary parenchyma [5]. The appearance of simple pulmonary hydatid cyst has been found in more than half of our patients $(53 \%)$. The ruptured pulmonary hydatid cyst achieves the appearance of a gaseous crescent pneumocyst, resulting in a clarity located at the upper pole of the opacity between the external wall of the cyst and the internal wall of the pericyst, this aspect is pathognomonic of the pulmonary hydatid cyst (Fig. 4). Intra-bronchial cyst rupture results in a hydro-aeric image with regular level (Fig. 5), corresponding either to the evacuation of the hydatid membranes, or to their total immersion in the hydatid fluid (Fig. 6) or by a hydro-aerated image with an irregular nipple level due to the floating membranes (the "water lily sign" or "camalote sign") (Fig. 7). Finally, a bridge image or "Ivassinevitch's double arc sign » is due to the partial detachment of the cyst membranes forming a bridge above the fluid level (Fig. 8). These last two aspects are pathognomonic of the ruptured pulmonary hydatid cyst [5]. It happens that all of the hydatid liquid is evacuated and only the mother membrane remains incarcerated in the residual cavity, this is the membrane retention phase achieving a round opacity with fuzzy limits, surrounded by a fine ring clarity, «cockade image» [2]. The pulmonary hydatid cyst completely empty of its content produces a roughly rounded image, limited by a more or less fine opaque strip [6].

\section{b) Ultrasound}

Ultrasound confirms the cystic nature, specifies the topography of a thoracic opacity relative to the diaphragm and eliminates the presence of an aberrant systemic vessel in favor of sequestration [7]. Chest ultrasound can distinguish several types of lesions (Fig. 9): simple anechoic cysts, heterogeneous ruptured cysts with posterior acoustic shadow cones reflecting the presence of air and cysts with a visible proliferous membrane, resulting in echogenic formation linear and wavy [2]. Abdominal ultrasound should be systematic in search of abdominal locations, especially hepatic [8]. The discovery of multiple pulmonary hydatidosis should always lead to a search for a primary cardiac location, hence the major interest of a systematic echocardiography. Thoracic ultrasound remains of limited use. Indeed a small or deep cyst is difficult to visualize. The osteoarticular envelope of the thorax and the alveolar air constitute the limits of this examination [2].

\section{c) Thoracic computed tomography}

It allows a precise study of the cyst and pericystic parenchyma, confirms the liquid nature and makes it possible to eliminate other etiologies. It makes it possible to detect small cysts, to determine their evolutionary stage, and above all to make a complete assessment of other possible thoracic localizations, which can go unnoticed on standard radiography [9].

The simple hydatid cyst results in a liquid mass limited by a thin and regular wall (Fig. 10). The pulmonary hydatid cyst can be single or multiple (Fig. 11).

The complications of pulmonary hydatid cyst are rupture in the bronchia (Fig. 12, 13, 14, 15, 16), bacterial infection, Loeffler's syndrome, it is caused by larval migration into the alveoli which triggers an allergic response leading to eosinophilic pneumonia with transient non-segmental areas of consolidation and cracked hydatid cyst (Fig. 17). The rupture in the bronchia goes through six evolutionary stages [10].

Stage I: It results from the entry of a minimal amount of air between the endocyst and the pericyst, this aspect is pathognomonic of the pulmonary hydatid cyst.

Stage II: aspect of "crescent" and "inverted crescent". It is due to the introduction of air between the endocyst and the pericyst with partial detachment of the endocyst.

Stage III: aspect of "trapped light" and "honeycomb". It is due to the total detachment of the endocyst without evacuation of the liquid contents. The aspect of "trapped clarities" is defined by the presence of small aeric bubbles within the liquid content. When the bubbles are numerous, they achieve the "honeycomb" appearance.

Stage IV: Hydro-aeric images. They are due to detachment of the endocyst with partial evacuation of the liquid content, realizing the aspect in "double arc" where the endocystis partially collapsed, of "water lily" or the endocyst completely collapsed floats on the liquid. If it remains completely submerged, it achieves a "serpiginous" aspect. These three aspects are pathognomonic of pulmonary hydatid cyst.

Stage V: appearance of dry retention. It is the result of a complete evacuation of the hydatid liquid and the retraction of the endocyst achieving an aspect of "ball of wool" or "bell" or a pseudo-tumor aspect.

Stage VI: after-effects. It is the result of a complete elimination of the content of the pulmonary hydatid cyst leaving an air cavity with a thin or thick wall or a dense linear non-septal image.

Rupture of a pulmonary hydatid cyst in the pleura is rare $(0.2 \%)$ [13], usually leading to hydropneumothorax (Fig.18), rarely pneumothorax [11]. 


\section{d) Magnetic resonance imaging}

Its essential interest is anatomical. It allows in difficult cases to establish the exact origin of the lesions.

\section{2) Extra-pulmonary hydatid cysts:}

The chest $\mathrm{x}$-ray remains a referral and rarely gives the exact diagnosis and location for extrapulmonary thoracic hydatid cysts. Ultrasound and chest CT are often useful in these cases for topographic and nature diagnosis [7].

\section{Pleural hydatid cysts}

It represents 1 to $2 \%$ of the thoracic hydatid localizations and it is dominated by the secondary parasitic graft [11]. Secondary pleural hydatidosis includes two different entities by their origin, their prognosis and their treatment. In the first case, pleural hydatidosis is secondary to the intra-pleural rupture of a pulmonary, diaphragmatic, hepatic (Fig. 19) or parietal hydatid cyst. In the second, it corresponds to an intrapleural transplant occurring during the surgical removal of a pulmonary hydatid cyst in connection with insufficient sterilization or accidental rupture of the cyst. In all cases, hydatid cysts tend to colonize the declining parts of the pleural cavity, especially the posterior pleural dead ends [11]. Secondary pleural hydatidosis is often diagnosed late and can be confused with multiple pulmonary hydatid cyst [12]. Primary pleural hydatidosis is evidenced by the absence of a history of pulmonary or hepatic hydatid cyst complicated by opening in the pleura. It is rare and difficult to assert [7].

\section{a) Chest x-ray}

The pleural hydatid cyst results in opacity of water tone, homogeneous, dense, realizing acute angles with the pulmonary parenchyma. This form is very rare, it is seen in the primitive forms, the limit of the standard radiography in this form is to determine the seat of the pleural or parietal cyst, pleural or mediastinal and sometimes pleural and pulmonary. The secondary pleural hydatid cyst usually results in a fluid effusion syndrome united or bilateral, more rarely by a pneumothorax [13].

\section{b) Ultrasound}

Ultrasound confirms the cystic nature of a thoracic opacity and looks for the partitions and the detachment of membranes in favor of a hydatid origin. It also specifies the filling of the ass of the sac in pleural effusion.

\section{c) Thoracic computed tomography}

It allows a precise study of cyst, confirms the liquid nature and seeks a pleural effusion, a pneumothorax and seeks the starting point in secondary and complicated forms (Fig 19). Secondary pleural hydatidosis is a diagnosis to be discussed in front of any patient originating from a hydatid endemic country, with a history of hydatid cyst and presenting with pleural symptoms. Its management requires precise mapping of hydatid locations, surgical treatment not without risk associated with medical treatment [14].

\section{1) Cardiac hydatid cysts}

Hydatid cysts of the heart are rare and represent only 0.2 to $3 \%$ of all hydatid localizations [15]. The symptomatology is very variable depending on the location and size of the cyst. It is often atypical and polymorphic symptoms, responsible for delayed diagnosis [16]. Chest pain is the most commonly reported symptom [17], it can be acute, simulating coronary syndrome [18]. The hydatid cyst can also simulate subaortic stenosis [19], pulmonary stenosis [20], mitral stenosis or tricuspid disease [21].

Breakage is the most serious complication. It can be done in the pericardium resulting in acute pericarditis with or without tamponade. This pericarditis can also progress to constriction. Rupture in the heart chambers leads to systemic [22] or pulmonary embolism [23]. The most frequent mode of revelation, however, remains the incidental discovery by chest radiography (which can show a localized arch, an extended deformation of an arch of the cardiac silhouette, or even associated pulmonary hydatidosis) or by transthoracic ultrasound [24].

The hydatid cyst is localized preferably at the level of the left ventricle (75\%), as in our case (Fig 20). This is due to the important muscular mass and the rich vascularization of the left ventricle; would explain the frequency of the localization of the hydatid cyst at this level [18]. Followed by the right ventricle (15\%); the interventricular septum (10\%); the atria (5 to 8\%) (Fig 21 ) and the pericardium in (4\%) [19] (Fig 22). The pure pericardial localization is quite exceptional [25]. The hydatid cyst of the heart is associated in 20 to $40 \%$ of cases with other visceral localizations [19] (Fig 23).

The electrocardiogram may show abnormalities in pseudo-ischemic repolarization in the left ventricle [26]. An atrioventricular block or right branch block is caused by an interventricular septum cyst [27].

Cardiac ultrasound remains the examination of the first intention to offer because of its safety, ease of use and good diagnostic performance [28]. Most often, the hydatid cyst appears as a rounded fluid formation that is homogeneous or contains vesicles (Fig. 20). More rarely the mass is full and corresponds to a ruptured cyst. The anechoic aspect immediately points towards a liquid mass and makes suspect hydatid nature in an endemic country [28]. However, ultrasound may be lacking in the diagnosis of small cysts $(<0.5 \mathrm{~cm})$, in the diagnosis of degenerate cysts containing membrane residues and necrotic material, finally in the distinction between single cyst and multilobulated cyst. 
At CT, the cardiac hydatid cyst looks like fluid formations in the heart muscle and inside the cavities (Fig 20), showing no change of density after injection of the contrast medium. The well visualized parietal calcifications are inconstant but suggestive. The CT makes it possible to carry out at the same time the assessment of extension of the disease by a thoraco abdominal acquisition in search of multi visceral localization. CT would be less efficient than echocardiography in locating cardiac hydatid cysts with precision [29], For Hamda et al., it does not provide any additional information compared to echocardiography [30].

In the published cases, the authors agree on the superiority of MRI [31]. Thanks to better spatial resolution and the possibility of carrying out a multiplanar study, MRI is the method of choice for the exploration of cardiac hydatidosis. MRI has a good sensitivity and makes it possible to make a positive diagnosis of small cystic formations. The hydatid cyst appears as a rounded formation in hypointense $\mathrm{T} 1$ and in hyperintenseT2 surrounded by a hypointense peripheral border. MRI allows a better diagnostic approach in case of atypical cyst [30]. The acquisition of sections in the different planes with cardiac synchronization makes it possible to pose the seat diagnosis with certainty. The study of the impact of cystic masses on cardiac function is made possible by the use of cine-MRI [32]. MRI allows a mediastinal extension assessment and to search for other hepatic, splenic and renal localizations.

The treatment is surgical because spontaneous evolution is fatal. Surgical treatment includes a cystectomy or at least an emptying of the cyst; which is sterilized by the intra-cystic injection of a parasiticidal solution (hypertonic saline). Treatment with associated fluoromebendazole has been recommended [33].

After the surgical intervention, clinical, electrocardiographic, biological, radiological and ultrasound surveillance is essential in the search for a possible recurrence.

\section{Vascular hydatid cysts}

The involvement of large vessels is exceptional and remains of poor prognosis. This rarity is explained by the need to cross the hepatic and pulmonary barriers by the scolex before reaching the coronary and pulmonary circulation [34].

The hydatid cyst of the right heart is often with subendocardial surface development. This explains the higher frequency of endocavitary rupture of the hydatid cyst of the right ventricle. It exposes to the risk of sudden death (29\% of cases) by massive pulmonary embolism, anaphylactic shock or blockage of a valve orifice [34]. The hematogenous dissemination of hydatid material secondary most often to the rupture of a hydatid cyst of the right ventricle [35], leads on the one hand to multiple lung lesions and on the other hand to central and peripheral pulmonary arterial lesions. The involvement of the pulmonary artery (PA) is therefore most often integrated in the context of right cardiac hydatidosis and it is exceptionally isolated [36] (fig 24).

The hydatid cyst of the pulmonary artery is formed from migrating daughter vesicles. Erosion of the endartery by the cyst is responsible for thinning of the vascular wall with formation of hydatid aneurysms, which increase the risk of hematogenous dissemination of hydatid material and massive hemoptysis by rupture in the bronchi [36].

Circulating water debris can lead to thrombosis of the branches of the pulmonary artery and become embedded in their walls. During embolic pulmonary hydatidosis, amputation of the pulmonary vascular bed by parasitic emboli on the one hand, destruction of the pulmonary parenchyma and bronchial changes on the other hand, lead to chronic respiratory failure and a chronic pulmonary heart [37].

The aortic location is exceptional. It is most often incidental of surgical discovery, or in the event of false aortic aneurysms [38]. It is exceptional and remains of very bad prognosis, due to the significant risk of rupture and dissemination to the other organs.

The opening of a hepatic hydatid cyst in the venous circulation, in particular in the inferior vena cava, the cysts can then migrate towards the right heart then towards the pulmonary artery thus real hydatid embolisms (Fig. 25).

Transthoracic ultrasound is the benchmark examination in the diagnosis of vascular hydatid cyst. However, its cost-effectiveness is lower than that of transesophageal echocardiography in the exploration of large vessels.

CT angiography is more effective than echocardiography in the diagnosis of hydatid cyst of the large Vessels. It allows the search for other intra thoracic hydatid localizations. The combination of echocardiography and computed tomography allows better accuracy of the type and location of the cyst. Angio MRI, which is a non-invasive examination and allows a complete lesion assessment. Only surgical treatment can ensure radical healing of the hydatid cyst and therefore remains the standard treatment.

\section{Mediastinal hydatid cyst}

Mediastinal localization of the hydatid cyst is extremely rare. It represents 0 to $4 \%$ of all locations [39]. It poses a diagnostic problem with other cystic lesions of the mediastinum, in endemic countries; the mediastinal hydatid cyst represents $4 \%$ of all mediastinal masses [39]. The pathogenesis of the mediastinal localization of the hydatid cyst remains 
poorly understood. It most often results from the secondary extension of a cardio-pericardial, vertebral, pleuro-pulmonary or retroperitoneal hydatidosis. More rarely, it is the result of a primary transplant by arterial or lymphatic route [40].

The mediastinal hydatid cyst is most often unique. The multiple nature is secondary to trauma, rupture of a primary cyst or thoracic surgery for hydatid cyst.

The clinical symptomatology is not specific represented by the signs of mediastinal compression. All localizations in the mediastinum are possible with a predilection for the posterior mediastinum. The posterior mediastinal hydatid cyst is the cause of pain, neurological signs associated or not with signs of vertebral or costal bone erosion. Localization in the middle mediastinum can cause fatal hemorrhage by vascular compression. At the level of the anterior mediastinum, the symptomatology is made of signs of tracheal compression or superior cavity [41].

Imaging is a fundamental element for positive diagnosis, assessment and monitoring. The front chest X-ray shows a widening of the mediastinum. Calcifications are rare and can guide the diagnosis [42]. Ultrasound is a second-line examination for exploring the mediastinum, especially in children and in anterior locations. She visualizes a thin-walled cystic formation, specifies its location and looks for the presence of partitions, proliferous membranes or membrane flow (Fig 26). In addition, ultrasound can detect any associated pleural or pericardial effusion. Abdominal exploration is systematically carried out in search of other hydatid localizations, notably hepatic, which associated with mediastinal involvement in $57 \%$ of cases [43].

The CT more precisely determines the compartment of the affected mediastinum. A predilection for the posterior compartment has been reported in the literature [43], although we have all the compartments of the mediastinum are affected (Fig 23, $24,26,27)$. It also makes it possible to seek the parietal calcifications, which are suggestive of diagnosis and to specify the relationships with the neighboring structures. CT is also very useful in locations at costovertebral angles where it assesses possible bone damage [44].

MRI is the examination of choice in exploring mediastinal hydatidosis. It makes it possible to better specify the topography of the cysts and the relationships with the neighboring organs thanks to the multi-planar sections [40]. The performance of multi-bar CT allows to postpone the MRI which is indicated in case of intolerance to iodine or in pregnant women [43]. These different means of sectional imaging (ultrasound, CT, MRI) allow, in most cases to differentiate the mediastinal hydatid cyst from other cystic masses of the mediastinum [45]. The existence of sub-diaphragmatic water locations is in favor of the hydatid nature of the mediastinal fluid mass. However, in a certain number of cases, a doubt persists and it is only in intraoperative that the diagnosis of mediastinal hydatid cyst made [46].

In front of a mediastinal cystic formation, other diagnoses must be discussed; including the cystic lymphangioma, which is most often not defined, multipartitioned, its wall is enhanced after injection of the contrast medium. The bronchogenic cyst is attached to the bronchial structures, has a spontaneously hyperdense appearance and thickened wall and can calcify on the periphery and does not enhanced after injection of the contrast medium. The enteric cyst sits at the posterior mediastinum and is often associated with vertebral abnormalities, the pleuro-pericardial cyst which has no identifiable wall but with a pericardial attachment. Treatment of the mediastinal hydatid cyst is surgical and consists of a cystectomy [47].

\section{Parietal hydatid cysts}

Thoracic parietal hydatidosis represents 0.09 to $3.3 \%$ of operated thoracic lesions. It can be costovertebral, diaphragmatic or more rarely sternal echinococcosis, hydatidosis of the soft tissues and most often both. The parasitic transplant can be primary, done hematogenously or secondary to spontaneous or intraoperative rupture of an Intra-thoracic hydatid cyst [48]. Parietal hydatidosis poses diagnostic problems with lesions of tumor or infectious origin. The clinical context and imagery often allow in these cases to guide the diagnosis.

\section{Diaphragmatic hydatid cysts}

The hydatid cyst of the diaphragm is defined by the development of a hydatid cyst in the thickness of the diaphragmatic muscle. It is a very rare pathology and its rarity is explained by the muscular contractility at the origin of a production of lactic acid preventing the fixation and the development of the parasite at the level of muscular tissue, in particular the diaphragm [48].The transplant is often primitive, done by arterial or lymphatic route. More rarely, the transplant is secondary to the rupture of a pulmonary or hepatic hydatid cyst. It can be associated with other intra- or extra thoracic localizations [49]. During its evolution, the hydatid cyst of the diaphragm can rupture in the pleura, the bronchi, in the abdominal cavity; become infected, or compress the adjacent organs. Clinically, the uncomplicated forms are asymptomatic and incidental discovery in $20 \%$ of cases. Elsewhere, the hydatid cyst of the diaphragm can manifest as thoracic base pain radiating to the shoulder and sometimes respiratory discomfort or irritative cough [50]. The diagnosis is based on imagery, in particular abdominal ultrasound which confirms the hydatid nature, but without certifying with certainty the diaphragmatic 
starting point. Chest and abdominal CT and / or magnetic resonance imaging (MRI) confirm the diaphragmatic origin. These various examinations also aim to look for a possible complication or another thoracic and abdominal location [51]. Hydatid serology is rarely positive when the diaphragmatic hydatid cyst is isolated and may remain negative after the intervention, even in the event of recurrence [48]. At the end of the various explorations, the diagnosis of the hydatid nature is generally posed, but it is especially the starting point of the hydatid cyst, which can remain imprecise before the surgical treatment [52]. The treatment is exclusively surgical. Depending on whether the development is at the expense of the upper or lower face of the diaphragm, the cyst will be approached by a thoracotomy or by a median or subcostal laparotomy [51].

\section{Costal hydatid cysts}

Bone echinococcosis is an exceptional attack, it represents 0.5 to $2.5 \%$ of all hydatid localizations [53]. Primary costal hydatidosis is exceptional even in the country of hydatidemia. Its evolution is slow and insidious over several years, and its symptomatology is poor and non-specific explaining the diagnostic delay [54].It is usually a swelling that increases in volume, whether or not associated with chest pain in the eye. Superinfection and fistulization of the skin are complications, which can also be a reason for consultation [55]. Imagery plays a dual role. It makes it possible to confirm the diagnosis of the hydatid cyst on the one hand, and to make the assessment of extension on the other hand. The reference examination is a thoracic or thoraco-abdominal computed tomography depending on the location of the lesion, allows a fine analysis of the costal bone lesions it is an image of intra-osseous fluid density with a thin wall, multilocular containing multiple hypodense cubicles, separated by partitions, not enhanced by the contrast medium, and containing no calcifications [56]. Ultrasound can guide the diagnosis; MRI only indicated in costo verbal locations with endocanal extension, its treatment is medico-surgical.

\section{Sternal hydatid cysts}

The sternal localization is exceptional. Less than a dozen cases are published in the literature. Bone localizations and in particular that of the sternum are generally primitive. Sternal involvement may be secondary to an intra-thoracic location: spontaneous or iatrogenic rupture of a pulmonary hydatid cyst in the pleura could be the cause of inoculation, especially the establishment of a post-operative thoracic drain [55]. Clinically, the disease is often asymptomatic. It evolves slowly, and is only revealed at a late stage by swelling and / or chest pain. It can also reveal itself following a complication such as suppuration or fistulization. The discovery can also be fortuitous through imagery. The chest radiograph shows a wide range of sternal osteolysis, multi lacunar with confluent gaps, separated from the healthy bone by a fuzzy transition zone, with no clear limit or periosteal reaction [57]. Thoracic ultrasound is the examination of choice that evokes the diagnosis. It shows an anechoic, thin-walled liquid formation, with or without membrane detachment, multi vesicular [57]. CT and MRI play a key role in positive diagnosis, the assessment of locoregional and remote extension, as well as postoperatively to ensure therapeutic efficacy and early detection of a possible recurrence

\section{Hydatid cysts of the muscles and thoracic soft tissue}

Hydatid cysts of the muscles and thoracic soft parts are exceptional, they are most often asymptomatic, rarely by a slow progressing subcutaneous swelling. Thoracic ultrasound is the examination of choice that evokes the diagnosis. CT and MRI play a key role in positive diagnosis, the assessment of loco-regional and distant extension, as well as postoperatively to detect early a possible recurrence (Fig. 28, 29).

\section{Vertebromedullary hydatid cysts}

The spine is most commonly affected by the disease. Dévé, in a study concerning 637 cases of echinococcosis, found a predominance of spinal involvement (44.2\%), long bones $(30 \%)$ and pelvis (16\%) [58]. Vertebro-medullary hydatidosis remains the most frequent and serious localization of hydatid disease in its bone form. In the majority of cases, it is a somatic bone involvement with an extension in the spinal canal. Spinal cord injury is secondary to the development of cysts inside the canal. This somatoepidural preponderance is explained by the richness of the vascularization of the vertebral body and the epidural space.

According to Braithwaite and Lees, vertebromedullary hydatidosis is classified into five groups

- Primitive intramedullarycyst;

- Primitive extramedullary intradural cyst;

- Primitive extradural cyst;

- Vertebralcyst;

- Para-vertebral cyst with spinal extension [59].

Spinal bone hydatidosis often occurs in the dorsal spine in $80 \%$ of cases, preferably between $\mathrm{T} 4$ and $\mathrm{T} 11$, rarely lumbar $18 \%$ lumbosacral and exceptionally cervical [60]. In vertebral involvement, the bone extends to the adjacent vertebral bodies, destroying the intervertebral discs, to the ribs and to the lumen of the spinal canal. The bony environment appears to confer relative malignancy to hydatidosis [60]. The soft structures that sit at the level of the posterior mediastinum constitute a factor favoring the volumetric extension of the hydatid cyst with local consequences like dyspnea, dysphagia and chest pain. The development of cystic mass and its extension in the spinal canal is responsible for spinal compression. Bone 
hydatidosis thus remains extradural as long as the dura mater remains intact.

The clinical signs of vertebral hydatidosis are not specific. It is a slowly evolving, long asymptomatic condition explaining the diagnostic delay [60]. Computed tomography studies the bone and clearly shows more or less well-limited lytic bone lesions, vertebral compression and disc damage when it exists. She appreciates the extension of the lytic lesions to the adjacent ribs very suggestive of hydatid disease and the extension of the cystic process towards the soft muscles of the lateral vertebral and mediastinal muscles. It highlights revealing signs of the hydatid origin of the cystic lesion, in particular the multilocular or multivesicular aspect and the image of intra cystic serpiginous membrane with the presence of a clean wall (figure 30). Magnetic resonance imaging is the examination of choice for spinal locations [61]. The interest of this examination lies in a greater precision in the study of the extension of lytic lesions, in height and especially to appreciate the extension of hydatid disease in intra thécale; by specifying the extension to the different compartments as well as compression of nerve structures [61]. The daughter vesicles, often innumerable in cases of extramedullary lesions, take an oblong shape with a thin wall without a septum. Their signal is pure liquid generally hypo signal in $\mathrm{T} 1$ and hyper signal in T2 not changing after injection of gadolinium. An enhancement can be seen on the periphery if the cyst is altered or infected (Fig. 30, 31, 32, 33) [61].

\section{CONCLUSION}

Given the high prevalence of hydatidosis in Mediterranean countries including Morocco, the nonspecificity of the clinical signs and its seriousness, which essentially lies in its complications, the diagnosis of hydatid cyst must be evoqued before any thoracic cystic lesion and its management must be adapted. The preventive aspect is essential. It is mainly based on cutting the parasite cycle by treating dogs and destroying the corpses of infested sheep.

\section{What is known on this subject?}

- There are a wide variety of thoracic localizations of hydatid cysts.

- Imaging plays a major role in the diagnostic assessment and assessment of extension and guides the therapeutic decision.

\section{What is new about your study?}

- The thoracic hydatid cysts differ in their clinical and radiological presentations, the aim of our work was to focus on these radiological features of each location.

\section{REFERENCES}

1. Achour, K., Ameur, S., \& Chaouche, H. (2013). Management of bilateral pulmonary hydatid cysts. Académie nationale de chirurgie, 12(3), 3843.

2. El Khattabi, W., Aichane, A., Riah, A., Jabri, H., Afif, H., \& Bouayad, Z. (2012). Analyse de la sémiologie radioclinique du kyste hydatique pulmonaire. Revue de Pneumologie clinique, 68(6), 329-337.

3. Salih, O. K., Topcuoğlu, M. Ş., Çelik, Ş. K., Ulus, T., \& Tokcan, A. (1998). Surgical treatment of hydatid cysts of the lung: analysis of 405 patients. Canadian journal of surgery, 41(2), 131.

4. RIFKL-JAI, S., BELMAHI, A., LAKHLOUFI, A., CHEHAB, F., \& KHAIZ, D. (2001). Le traitement chirurgical du kyste hydatique du poumon: A propos de 184 cas. Maghreb médical, (357), 192194.

5. Larbaoui, D. (1989). Le kyste hydatique du poumon. Revue de pneumologie clinique (Paris), 45(2), 49-63.

6. Khalil, M. (2006). Traitement de l'hydatidose thoracique (Doctoral dissertation, Thèse médicale, Rabat).

7. Bouhaoula, M.H., Hendaoui, L., Charfi, M.R., Drissi, C., Tlili-Graies, K., Mechmeche, R. (2007). Hydatidose thoracique. Radiol Imagerie Med;32: 470-A, 20.

8. Gamondes, J.P., Devolfe, C., Maret, G. (1983). Double localisation hydatique pulmonaire et hepatique (4 observations). Ann Chir Thorac Cardiovasc, 37:109-10.

9. Racil, H., Amar, J. B., Moulay, R. E. F., Ridene, I., Cheikrouhou, S., Zarrouk, M., ... \& Chabbou, A. (2009). Kystes hydatiques compliqués du poumon. Revue des maladies respiratoires, 26(7), 727-734.

10. Zidi, A., Miled-Mrad, K. B., Hantous-Zannad, S., Fathallah, B., Mestiri, I., Baccouche, I., \& Djilani, H. (2007). Kyste hydatique du poumon ouvert dans les bronches: apport de la tomodensitometrie. Journal de Radiologie, 88(1), 59-64.

11. Elkard, I., Benjelloun, H., Zaghba, N., Bakhatar, A., Yassine, N., \& Bahlaoui, A. (2015). L'hydatidose pleurale secondaire. Revue des Maladies Respiratoires, 32, A166.

12. Aguilar, X., Fernandez-Muixi, J., Magarolas, R., Sauri, A., Vidal, F., \& Richart, C. (1998). An unusual presentation of secondary pleural hydatidosis. European Respiratory Journal, 11(1), 243-245.

13. Marghli, A., Ayadi-Kaddour, A., Ouerghi, S., Boudaya, M. S., Zairi, S., Smati, B., ... \& Kilani, T. (2011). Un pneumothorax révélateur d'une hydatidose pleurale primitive hétérotopique. Revue des maladies respiratoires, 28(3), 344-347.

14. Zekri, E. B. J. B., Zairi, S., Gharssali, H., Abdenadher, M., Zribi, H., Ayadi, A., \& Marghli, A. (2019). Profil clinique et particularités thérapeutiques de l'hydatidose pleurale 
secondaire. Revue des Maladies Respiratoires, 36, A153.

15. Struillou, L., Rabaud, C., Bischoff, N., Preiss, M. A., \& May, T. (1997). Complications du kyste hydatique cardiaque: 2 observations. La Presse médicale (1983), 26(25), 1192-1194.

16. Onursal, E., Elmac1, T. T., Tirel1, E., Dindar, A., At1lgan, D., \& Özcan, M. (2001). Surgical treatment of cardiac echinococcosis: report of eight cases. Surgery today, 31(4), 325-330.

17. Benomar, A., Yahyaoui, M., Birouk, N., Vidailhet, M., \& Chkili, T. (1994). Middle cerebral artery occlusion due to hydatid cysts of myocardial and intraventricular cavity cardiac origin. Two cases. Stroke, 25(4), 886-888.

18. Sarkis, A., Ashoush, R., Alawi, A., Haddad, A., Jebara, V., \& Checrallah, E. (2001, January). Kyste hydatique du cœur simulant une ischémie coronarienne. In Annales de cardiologie et d'angeiologie (Vol. 50, No. 4, pp. 206-210). Elsevier Masson.

19. JERBI, S., KORTAS, C., DAMMAK, S., HAMIDA, N., \& ALY, F. (2004). Les kystes hydatiques cardio-péricardiquis. A propos de 19 observations. Tunisie médicale, 82, 152-157.

20. Russo, G., Tamburino, C., Cuscuná, S., Arcidiacono, G., Foti, R., Grimaldi, D. R., ... \& Giuffrida, G. (1989). Cardiac hydatid cyst with clinical features resembling subaortic stenosis. American heart journal, 117(6), 13851387.

21. Lanzoni, A. M., Barrios, V., Moya, J. L., Epeldegui, A., Celemin, D., Lafuente, C., \& AsinCardiel, E. (1992). Dynamic left ventricular outflow obstruction caused by cardiac echinococcosis. American heart journal, 124(4), 1083-1085.

22. Erol C, Candan I, Akalin H, Sonel A, Kervancioglu C. Cardiac hydatid cyst simulating tricuspid stenosis. Am J Cardiol1985; 56 : 833-4

23. Palant, A., Deutsch, V., Kishon, Y., Lieberman, Y., Yahini, J. H., \& Neufeld, H. N. (1976). Pulmonary hydatid embolization. Report on 2 operated cases and review of published reports. Heart, 38(10), 1086-1091.

24. Thameur, H. (2001). Cardio-pericardial hydatid cysts. World Journalof Surgery, 25:58-67.

25. Tedy, G., Maamari, S., Khoury, J., Heraoui, E., \& Karam, G. (1995). Kystes hydatiques péricardiques: intérêt de'imagerie par résonance magnétique: à propos d'un cas clinique. In Annales de cardiologie et d'angéiologie (Paris) (Vol. 44, No. 6, pp. 280-283).

26. Sarkis, A., Ashoush, R., Alawi, A., Haddad, A., Jebara, V., \& Checrallah, E. (2001, January). Kyste hydatique du cœur simulant une ischémie coronarienne. In Annales de cardiologie et d'angeiologie (Vol. 50, No. 4, pp. 206-210). Elsevier Masson.
27. Agarwal, D. K., Agarwal, R., \& Barthwal, S. P. (1996). Interventricular septal hydatid cyst presenting as complete heart block. Heart, 75(3), 266.

28. Bennis, A., Chraïbi, S., Noureddine, M., Bennami, C., Soulami, S., Chraïbi, N. (1996). Apport de l'imagerie par résonnance magnétique dans l'hydatidose cardiaque. À propos d'un cas. Ann Cardiol Angéiol, 45, 132-5.

29. Kardaras, F., Kardara, D., Tselikos, D., Tsoukas, A., Exadactylos, N., Anagnostopoulou, M., ... \& Anthopoulos, L. (1996). Fifteen year surveillance of echinococcal heart disease from a referral hospital in Greece. European heart journal, 17(8), 1265-1270.

30. Ben-Hamda, K., Maatouk, F., Ben-Farhat, M., Betbout, F., Gamra, H., Addad, F., ... \& Hendiri, T. (2003). Eighteen-year experience with echinococcosus of the heart: clinical and echocardiographic features in 14 patients. International journal of cardiology, 91(23), 145-151.

31. Vanjak, D., Moutaoufik, M., Leroy, O., Beuscart, C., \& Billiau, V. (1990). Hydatidose cardiaque: apport de l'imagerie par résonance magnétique. A propos d'un cas. Archives des maladies du coeur et des vaisseaux, 83(11), 1739-1742.

32. Baqué, J., Huart, V., Pierrot, J. M., Louail, B., \& Grinda, J. M. (2003). Kyste hydatique du septum interventriculaire du coeur: aspect en scanner multibarrette et en IRM. Journal de radiologie (Paris), 84(5), 614-616.

33. Nour-Eddine, M., Habbal, R., Haddani, J., Mehadji, B. Z., \& Chraibi, N. (2000). Épanchement péricarclique révélateur d'une hydatidose médiastinale: A propos d'un cas. Archives des maladies du coeur et des vaisseaux, 93(1), 95-99.

34. Trehan, V., Shah, P., Yusuf, J., Mukhopadhyay, S., Nair, G. M., \& Arora, R. (2002). Thromboembolism: a rare complication of cardiac hydatidosis. Indian heart journal, 54(2), 199-201.

35. Sabah, I., Yalcin, F., \& Okay, T. (1998). Rupture of a presumed hydatid cyst of the interventricular septum diagnosed by transoesophageal echocardiography. Heart, 79(4), 420-421.

36. Talmoudi, T., \& JJ, R. (1980). L'embolie pulmonaire hydatique. Etude de deux observations personnelles et revue de la litterature.

37. Jeridi, G., Hmouda, H., Ernez Hajri, S., Hediji, A., \& Ammar, H. (1996). Kyste hydatique du ventricule droit compliqué d'un cœur pulmonaire aigu. La Semaine des hôpitaux de Paris, 72(31-32), 985-988.

38. Zaghba, N., Yassine, N., Bakhatar, A., \& Bahlaoui, A. (2010). Hydatidose pulmonaire multiple avec localisation cardiaque, artérielle pulmonaire et aortique. Revue de Pneumologie clinique, 66(3), 197-200.

39. Khannous, M., Ferretti, G., Ranchoup, Y., Thony, F., Robert, F., Coulomb, M. (1993). Kyste 
hydatique intrathoracique. Contribution de la tomodensitométrie. À propos de 25 cas. J Radiol, 7(11):541-8.

40. El Abbassi Skalli, A., Elamouri, F., Chikhaoui, N. (2000). Kyste hydatique du médiastin : À propos de 2 cas. J Radiol, 81:154-7.

41. Aloui-Kasbi, N., Chennoufi, F., Boussetta, K., Bellagha, I., Chaouachi, B., \& Hammou, A. (2004). Kyste hydatique médiastinal. Une nouvelle observation. Journal de pédiatrie et de puériculture, 17(6), 312-315.

42. Von Sinner, W. N., \& Linjawi, T. (1990). Mediastinal hydatid disease: report of three cases. Canadian Association of Radiologists journal= Journal l'Association canadienne des radiologistes, 41(2), 79-82.

43. Zidi, A., Zannad-Hantous, S., Mestiri, I., Ghrairi, H., Baccouche, I., Djilani, H., \& Mrad, K. B. M. (2006). Kyste hydatique primitif du médiastin: 14 cas. Journal de radiologie, 87(12), 1869-1874.

44. Beji, M., Messaoud, M. B., Louzir, B., Bouzaïdi, K., Rhouma, N. H. B., Cherif, J., ... \& Daghfous, J. (2004). Localisation cervico-thoracique d'un kyste hydatique. Journal de Radiologie, 85(2), 135-137.

45. Benzarti, M., Jerray, M., Khirouni, S., Souissi, J., \& OMMEZZINE, N. (1997). Kyste hydatique médiastinal primitif compressif calcifié. Revue des maladies respiratoires, 14(1), 53-54.

46. Kabiri, E. H., Aziz, S. A., Maslout, A. E., \& Benosman, A. (2001). Hydatid cyst: an unusual disease of the mediastinum. Acta Chirurgica Belgica, 101(6), 283-286.

47. Purohit, M. (2003). Primary hydatid cysts of the mediastinum. European journal of cardio-thoracic surgery: official journal of the European Association for Cardio-thoracic Surgery, 23(2), 257-258.

48. Kabiri, H., Al Aziz, S., El Maslout, A., \& Benosman, A. (2001). L'hydatidose diaphragmatique: A propos d'une série de 27 cas. Revue de pneumologie clinique (Paris), 57(1), 13-19.

49. Skljarov, I., Celard, P., Gamondes, J. P., \& Pinet, F. (1985). Les tumeurs primitives du diaphragme. A propos d'un cas. Journal de radiologie (Paris), 66(8-9), 527-530.
50. Daali, M., Hssaida, R. (2000). L'hydatidose musculaire. Presse Med, 29:1166-9.

51. Makni, A., Fetirich, F., Jouini, M., Kacem, M., \& Safta, Z. B. (2012). Kyste hydatique primitif et isolé du diaphragme en Tunisie. Bulletin de la Société de pathologie exotique, 105(4), 262-264.

52. De Vega, D. S., Vazquez, E., Calvo, E., \& Tamames, S. (1991). Kyste hydatique du diaphragme: a propos d'un cas. Journal de chirurgie (Paris. 1908), 128(2), 76-78.

53. Ouadnounia, Y., Bouchikha, M., Achira, A., Smahia, M., Msougara, B, Y., Lakranbia, M., Alaziza, A.S. (2011). Benosmana. Hydatidose costale, Revue des Maladies Respiratoires, 28, 306311.

54. Belliraj, L., Lakranbi, M., Ammor, F. Z., Harmouchi, H., Ouadnouni, Y., \& Smahi, M. (2019). Kyste hydatique costal primitif: localisation hydatique exceptionnelle.

55. Rabiou, S., Ghalimi, J., Issoufou, I., Lakranbi, M., Ouadnouni, Y., \& Smahi, M. (2016). Hydatidose osseuse de la paroi thoracique: à propos de trois cas. Revue de Pneumologie clinique, 72(4), 264268.

56. Beji, M., Messaoud, M. B., Louzir, B., Bouzaïdi, K., Rhouma, N. H. B., Cherif, J., ... \& Daghfous, J. (2004). Localisation cervico-thoracique d'un kyste hydatique. Journal de Radiologie, 85(2), 135-137.

57. Benrami, M., Bouklata, S., Asefsa, Z., Hammani, L., \& Imani, F. (2007). Le kyste hydatique du sternum: une localisation rare. Journal de radiologie (Paris), 88(2), 277-279.

58. Devé, F. (1948). L'échinococcose osseuse vertébrale. Paris: Masson.

59. Braithwaite, P. A., \& Lees, R. F. (1981). Vertebral hydatid disease: radiological assessment. Radiology, 140(3), 763-766.

60. Semlali, S., Nassar, I., Cisse, A. (2004). Hydatidose vertébromédullaire cervical étendue au pharynx : à propos d'une observation. J Radiol, 85:51-3.

61. Alimi, F., Limayem, F., Mgarrech, I., Marzouk, M., Jerbi, S., Mlika, S., \& Ennabli, K. (2012). Kyste hydatique vertébral primitif à extension médiastinale postérieure compliquée d'une paraplégie. Revue des maladies respiratoires, 29(7), 908-911.

Cite This Article: Baadi F et al (2021). Imaging of Thoracic Hydatid Cysts, Point of view of the Radiologist. EAS J Radiol Imaging Technol, 3(2), 82-101. 